Linköping Studies in Science and Technology

Dissertation No. 1576

\title{
Transition metal carbide nanocomposite and amorphous thin films
}

\section{Olof Tengstrand}

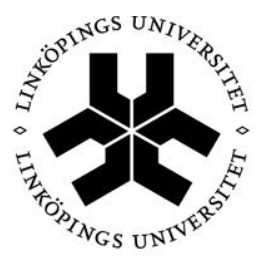

\section{Linköping University}

INSTITUTE OF TECHNOLOGY

Thin Film Physics Division

Department of Physics, Chemistry and Biology (IFM)

Linköping University

SE-581 83 Linköping, Sweden 
The cover image shows a high resolution transmission electron microscopy image of a nanocomposite structure consisting of crystalline titanium carbide grains in an amorphous matrix of silicon and carbon. On the backside part of a selected area electron diffraction pattern from the same film is also seen.

(C) Olof Tengstrand 2014

ISBN: 978-91-7519-398-4

ISSN: 0345-7524

Printed by LiU-Tryck

Linköping, Sweden, 2014 


\section{Abstract}

This thesis explores thin films of binary and ternary transition metal carbides, in the Nb-C, Ti-Si-C, Nb-Si-C, Zr-Si-C, and Nb-Ge-C systems. The electrical and mechanical properties of these systems are affected by their structure and here both nanocomposite and amorphous thin films are thus investigated. By appropriate choice of transition metal and composition the films can be designed to be multifunctional with a combination of properties, such as low electric resistivity, low contact resistance and high mechanical strength. Electrical contacts are one example of application that has been of special interest in this thesis. Since some industrially important substrates used in electrical contacts soften at higher temperature, all films were deposited with dc magnetron sputtering at a low substrate temperature $\left(200-350{ }^{\circ} \mathrm{C}\right)$.

I show that the electrical resistivity and mechanical properties of composites consisting of nanocrystalline $\mathrm{NbC}$ grains $(\mathrm{nc}-\mathrm{NbC}$ ) in a matrix of amorphous $\mathrm{C}$ (a-C) depend strongly on the amount of amorphous $\mathrm{C}$. The best combination of hardness $(23 \mathrm{GPa})$ and electrical resistivity $(260 \mu \Omega \mathrm{cm})$ are found in films with $\sim 15$ at.\% a-C phase. This is a higher hardness and lower resistivity than measured for the more well studied Ti-C system if deposited under similar conditions. The better results can be explained by a thinner matrix of amorphous $\mathrm{C}$ phase in the case of $\mathrm{NbC}$. The nc-NbC/a-C is therefore interesting as a material in electrical contacts.

Si can be added to further control the structure and thereby the properties of binary $\mathrm{Me}-\mathrm{C}$ systems. There are however, different opinions in the literature of whether $\mathrm{Si}$ is incorporated on the $\mathrm{Ti}$ or $\mathrm{C}$ site in the cubic $\mathrm{NaCl}$ (B1) structure of $\mathrm{TiC}$. In order to understand how $\mathrm{Si}$ is incorporated in a Me-Si-C material I use a model system of epitaxial $\mathrm{TiC}_{\mathrm{x}}(\mathrm{x} \sim 0.7)$. In this model system a few atomic percent of $\mathrm{Si}$ can be incorporated in the cubic TiC structure. The experimental results together with theoretical stability calculations suggest that the $\mathrm{Si}$ is positioned at the $\mathrm{C}$ sites forming $\mathrm{Ti}(\mathrm{Si}, \mathrm{C})_{\mathrm{x}}$. The calculation further shows a strong tendency for $\mathrm{Si}$ segregation, which is seen at higher Si contents in the experiments, where Si starts segregate out from the $\mathrm{TiC}_{\mathrm{x}}$ to the grain boundaries causing a loss of epitaxy.

If $\mathrm{Si}$ is added to an $\mathrm{Nb}-\mathrm{C}$ nanocomposite, it hinders the grain growth and thus a reduced size of the $\mathrm{NbC}$ grains is observed. The $\mathrm{Si}$ segregates to the amorphous matrix forming a-SiC. At the same time the resistivity increases and the hardness is reduced. With even higher amounts of $\mathrm{Si}(>25$ at.\%) into the $\mathrm{Nb}-\mathrm{Si}-\mathrm{C}$ material, grain growth is no longer possible and the material becomes amorphous. In order to separate between effects from the addition of $\mathrm{Si}$ and the choice of transition metal I compare the $\mathrm{Nb}-\mathrm{Si}-\mathrm{C}$ system to already published results for the $\mathrm{Zr}-\mathrm{Si}-\mathrm{C}$ system. I find that the hardness of the material depends on the amount of strong 
$\mathrm{Si}-\mathrm{C}$ bonds rather than the type of transition metal. The reduced elastic modulus is, however, dependent on the choice of transition metal. I therefore suggest that it is possible to make $\mathrm{Me}-\mathrm{Si}-\mathrm{C}$ films with high wear resistance by an appropriate choice of transition metal and composition.

Electron microscopy was of importance for determining amorphous structures of $\mathrm{Nb}-\mathrm{Si}-\mathrm{C}$ and $\mathrm{Zr}-\mathrm{Si}-\mathrm{C}$ at high $\mathrm{Si}$ contents. However, the investigations were obstructed by electron beam induced crystallization. Further investigations show that the energy transferred from the beam electrons to $\mathrm{C}$ and $\mathrm{Si}$ atoms in the material is enough to cause atomic displacements. The displacements cause volume fluctuations and thereby enhance the mobility of all the atoms in the material. The result is formation of $\mathrm{MeC}$ grains, which are stable to further irradiation.

Finally, I have studied substitution of $\mathrm{Ge}$ for $\mathrm{Si}$ in a ternary system looking at $\mathrm{Nb}-\mathrm{Ge}-\mathrm{C}$ thin films. I show that the films consist of nc-NbC/a-C/a-Ge and that $\mathrm{Ge}$ in a similar way to $\mathrm{Si}$ decreases the size of the crystalline $\mathrm{NbC}$ grains. However, a transition to a completely amorphous material is not seen even at high $\mathrm{Ge}$ contents ( 30 at.\%). Another dissimilarity is that while Si bonds to $\mathrm{C}$ and forms a matrix of a-SiC, Ge tends to bond to $\mathrm{Ge}$. 


\section{Populärvetenskaplig sammanfattning}

\section{Tunna filmskikt för bättre materialegenskaper}

Ett material kan beskrivas med en eller flera karaktäristiska egenskaper. Järn är till exempel hårt, men rostar lätt $\mathrm{i}$ fuktiga miljöer. För att skydda järn från rost kan man tillsätta andra grundämnen så att rostfritt stål bildas. Alternativt målas järnet med en rostfri färg. I min forskning applicerar jag ett tunt skikt som inte tjockare än 1/100 av diametern på ett hårstrå av ett material ovanpå ett annat för att förändra egenskaperna på ytan. Liksom man inte bara väljer färg efter dess vädertålighet utan även dess kulör, kan man ofta kombinera flera olika önskvärda egenskaper genom ett smart val av olika grundämnen i sitt tunna filmskikt. Själv försöker jag hitta ett material som ska fungera bra i en elektrisk kontakt, som i exempelvis en mobiltelefonladdare. Här behöver vi kombinera skydd mot oxidation med god ledningsförmåga och nötningstålighet. Målet med forskningen är att kunna byta ut de ämnen som ofta används idag (silver och guld), vilka både är dyra och ofta beläggs i processer som använder miljöfarliga kemikalier. Nu ska beläggningarna ske $\mathrm{i}$ vakuum och med renast möjliga förhållanden.

Ett material som redan har visat sig fungera som tunnfilm på elektriska kontakter är en kombination av titan och kol. Detta material består av små hårda korn av titankarbid omgivna av mjukare kol (ungefär som en småkaka med chokladbitar i). Jag har i min forskning prövat att byta ut titan mot niob eftersom dessa grundämnen ligger nära varandra i det periodiska systemet och har liknande egenskaper. Den skillnad jag upptäckte är att det i filmer innehållande niob finns mindre omgivande kol. (Samma mängd chokladbitar, men mindre kaksmet.) Detta är fördelaktigt om man vill leda ström genom filmen eftersom kolet inte leder ström så bra. Min slutsats är därför att niob-kol-materialet fungerar minst lika bra som titan-kol när det gäller att tillverka en elektrisk kontakt.

Ibland kan det vara nödvändigt att tillsätta ett tredje grundämne för att ytfilmen ska få alla de egenskaper man önskar. Det är i så fall viktigt att förstå var detta grundämne sätter sig och hur strukturen i materialet förändras. I min forskning handlar det om att tillsätta kisel i titankarbid. I ren titankarbid sitter titan- och kolatomerna på ett välordnat sätt. Om man sedan tillsätter små mängder kisel så sätter sig kiselatomerna på samma plats som kolatomer skulle gjort och strukturen bevaras. Kiselatomer vill dock hellre sitta utanför titan-kol-strukturen. Med större mängder kisel bryts därför den välordnade strukturen sönder. Kvar blir mindre korn av titankarbid. Inne i dessa sitter titan- och kolatomer fortfarande på ett välordnat sätt. Runtom kornen sätter sig kisel- och kolatomer på ett helt oordnat sätt. Ju mer kisel desto mindre blir kornen. Kisel kan därför användas till att styra kornstorleken och därmed påverka till exempel hårdheten i detta material. 
Samma förändring i strukturen sker med tillsatser av kisel i niobkarbid. Om antalet kiselatomer är fler än en fjärdedel av det totala antalet atomer förloras strukturen helt och samtliga atomer hamnar på ett slumpmässigt och oordnat sätt. Ett glasartat, s.k. amorft, material skapas då. Detta är inte till någon fördel för de elektriska egenskaperna eftersom det inte finns någon välordnad struktur där strömmen enkelt kan ta sig fram, men bra ur ett perspektiv där det handlar om att skydda det underliggande materialet mot till exempel nötning.

För att beskriva strukturen och detaljerna hos mina material har jag studerat dem med atomär upplösning i ett transmissionselektronmikroskop (TEM). Detta mikroskop fungerar på samma sätt som vanligt ljusmikroskop, men i stället för synligt ljus använder jag mig av elektroner för att avbilda materialet. Att jag använder mig av elektroner beror på att dessa kan ge en högre upplösning än synligt ljus. I princip fås en bättre upplösning ju högre energi elektronerna har och därför använder jag elektroner med mycket hög energi. Faran är dock att en del av denna energi överförs till materialet och förändrar strukturen.

Jag har därför undersökt elektronstråle-inducerade förändringar i filmer av zirkonium-kisel-kol och niob-kisel-kol. Från början sitter atomerna i dessa material helt oordnat men efter några minuters elektronbestrålning bildas korn av zirkonium-kol respektive niob-kol. Det är därför viktigt att vara observant om man studerar denna typ av material i elektronmikroskop. Genom flera olika experiment kom jag fram till att förändringarna beror på att kol- och eventuellt kiselatomer kan flytta på sig om en elektron skulle kollidera rakt in i en sådan atomkärna. För att undvika denna typ av skador kan man antingen sänka energin hos de inkommande elektronerna för att förhindra skadan eller vara så snabb i exponeringen att provet inte hinner påverkas. 


\section{Preface}

I here present the outcome of my years of work as a PhD-student in the Thin Film Physics Division at Linköping University. The thesis has been performed within Theme 1 of the VINN Excellence Center on Functional Nanoscale Materials (FunMat). The research was carried out in cooperation with Uppsala University, Technical Research Institute of Sweden (SP), and the companies Impact Coatings $\mathrm{AB}$ and $\mathrm{ABB} \mathrm{AB}$. The present $\mathrm{PhD}$ Thesis is an expansion of my Licenciate Thesis (No. 1561, Linköping Studies in Science and Technology), which was presented in December 2012. 


\section{Included papers}

\section{Paper 1}

Structural, mechanical and electrical-contact properties of nanocrystalline-NbC/amorphous-C coatings deposited by magnetron sputtering N. Nedfors, O. Tengstrand, E. Lewin, A. Furlan, P. Eklund, L. Hultman, U. Jansson

Surface and Coatings Technology 206 (2011) 354-359

\section{Paper 2}

Incorporation effects of $\mathrm{Si}$ in $\mathrm{TiC}_{x}$ thin films

O. Tengstrand, N. Nedfors, B. Alling, U. Jansson, A. Flink, P. Eklund, L. Hultman.

Manuscript in preparation

\section{Paper 3}

Characterization of amorphous and nanocomposite $\mathrm{Nb}$-Si-C thin films deposited by DC magnetron sputtering

N. Nedfors, O. Tengstrand, A. Flink, P. Eklund, L. Hultman, U. Jansson Thin Solid Films 545 (2013) 272-278

\section{Paper 4}

Beam-induced crystallization of amorphous $\mathrm{Me}-\mathrm{Si}-\mathrm{C}(\mathrm{Me}=\mathrm{Nb}$ or $\mathrm{Zr})$ thin films during transmission electron microscopy

O. Tengstrand, N. Nedfors, M. Andersson, J. Lu, U. Jansson, A. Flink, P. Eklund, L. Hultman

MRS Communications 3(3) (2013) 151-155

\section{Paper 5}

Model for electron-beam-induced crystallization of amorphous $\mathrm{Me}-\mathrm{Si}$-C $(\mathrm{Me}=\mathrm{Nb}$ or Zr) thin films

O. Tengstrand, N. Nedfors, M. Andersson, J. Lu, U. Jansson, A. Flink, P. Eklund, L. Hultman

Manuscript in preparation

\section{Paper 6}

Structure and electrical properties of $\mathrm{Nb}-\mathrm{Ge}$-C nanocomposite coatings

O. Tengstrand, N. Nedfors, L. Fast, A. Flink, U. Jansson, P. Eklund,

L. Hultman

Manuscript in preparation 


\section{My contribution to included papers}

\section{Paper 1}

I carried out all TEM characterization and contributed to writing the paper.

\section{Paper 2}

I took part in the planning of the work, performed most of the experimental work, analyzed the results and wrote the paper. I discussed the simulation structures with Björn Alling, who performed the theoretical calculations.

\section{Paper 3}

I carried out all TEM characterization and contributed to writing the paper.

\section{Paper 4}

I was responsible for planning the work, performed most of the experimental work, analyzed the results, and wrote the paper.

\section{Paper 5}

I was responsible for planning the work, performed most of the experimental work, analyzed the results, and wrote the paper.

\section{Paper 6}

I took part in the planning of the work, performed most of the experimental work, analyzed the results, and wrote the paper. 


\section{Related papers not included in the thesis}

\section{Paper 7}

Phase-stabilization and substrate effects on nucleation and growth of $(\mathrm{Ti}, \mathrm{V})_{n+1} \mathrm{Ge}_{n}$ thin films

S. Kerdsongpanya, K. Buchholt, O. Tengstrand, J. Lu, J. Jensen, L. Hultman, P. Eklund

Journal of Applied Physics 110 (2011) 053516

\section{Paper 8}

Discovery of the ternary nanolaminated compound $\mathrm{Nb}_{2} \mathrm{GeC}$ by a systematic theoretical-experimental approach

P. Eklund, M. Dahlqvist, O. Tengstrand, L. Hultman, J. Lu, N. Nedfors, U. Jansson, J. Rosén

Physical Review Letters 109 (2012) 035502

\section{Paper 9}

Reactive sputtering of $\mathrm{NbC}_{x}$-based nanocomposite coatings: an up-scaling study N. Nedfors, O. Tengstrand, A. Flink, P. Eklund, L. Hultman, U. Jansson Manuscript in preparation

\section{Paper 10}

Superhard $\mathrm{NbB}_{2-x}$ thin films deposited by dc magnetron sputtering

N. Nedfors, O. Tengstrand, J. Lu, P. Eklund, P.O.A. Persson, L. Hultman, U. Jansson

Submitted for publication

\section{Paper 11}

Study of $\mathrm{Nb}-\mathrm{B}-\mathrm{C}$ thin films for electrical contact applications deposited by magnetron sputtering

N. Nedfors, O. Tengstrand, P. Eklund, L. Hultman, U. Jansson

Manuscript in final preparation

\section{Paper 12}

Si incorporation in $\mathrm{Ti}_{1-x} \mathrm{Si}_{x} N$ films grown on TiN(001) and (001)-faceted TiN(111) columns

A.O Eriksson, O. Tengstrand, J. Lu, J. Jensen, P. Eklund, J. Rosen, I. Petrov, J. E. Greene, L. Hultman

Submitted for publication 


\section{Acknowledgements}

To remember all persons who should be mentioned in this section must be one of the hardest things in writing a thesis. During the years I have met a lot of people that have helped me in a numerous different ways. Of course we have all coauthors that helped me in bringing scientific results out to this world, but also all you others. With some of you I have been exploring the world at conferences. With others I have been wrestling with problems in different courses. Many of you are giving me good company at lunches, physical training or in the office. Thanks for cheering me up, reminding me to take breaks, help and interesting discussions in both work and non-work related topics.

A special thanks to:

My supervisor, Lars Hultman, and co-supervisors, Per Eklund and Axel Flink, for sharing your knowledge and wisdom. You have been a great help!

Jun Lu, for giving help and advice in about almost everything concerning electron microscopy.

Thomas Lingefelt, for all the times you fixed the instruments I needed.

Nils Nedfors and Ulf Jansson at Uppsala University. Without you my papers would not be the same.

Sara, for support and patience when my work sometimes has taken a little bit longer time than planned.

In some sense I feel sad for finishing, since this marks the ending of something that have been a most interesting part of my life during the past five years. In other ways I feel relieved that it's over. Most of all I think I'm excited about the future. I hope to meet you there!

/Olof 



\section{Contents}

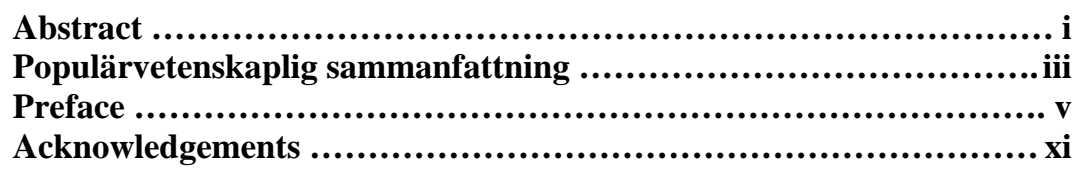

1. Introduction ...................................................................1

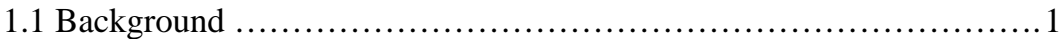

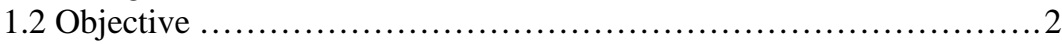

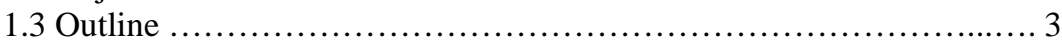

2. Electrical contacts .....................................................5

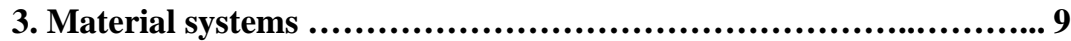

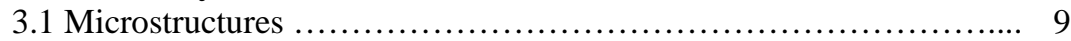

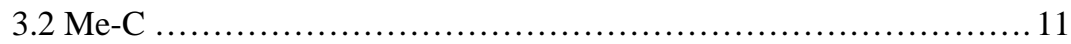

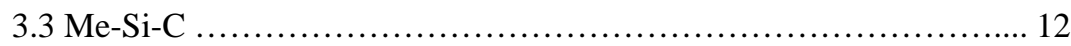

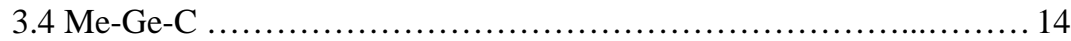

4. Deposition processes ....................................................... 19

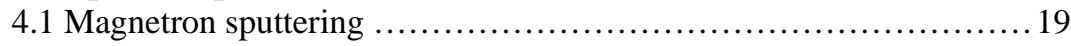

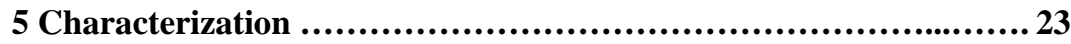

5.1 Transmission electron microscopy (TEM) ......................... 23

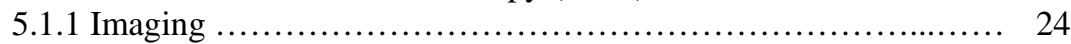

5.1.2 Energy-dispersive X-ray Spectroscopy (EDX) …..................26

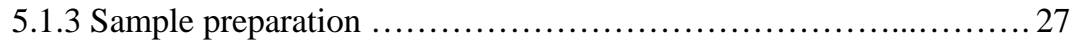

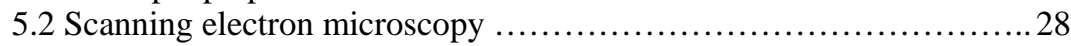

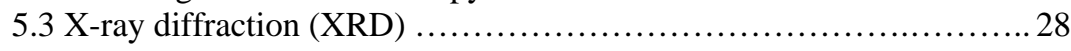

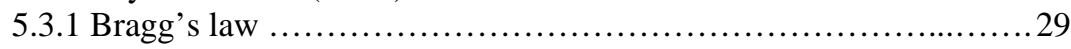

5.3.2 Different X-ray diffraction methods used ........................... 29

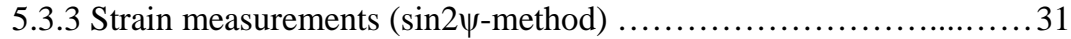

5.3.4 X-ray reflectivity (XRR) …..................................... 32

5.4 X-ray photoelectron spectroscopy (XPS) …....................... 33

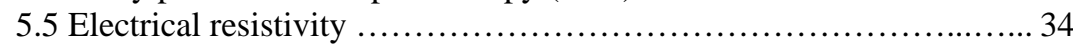

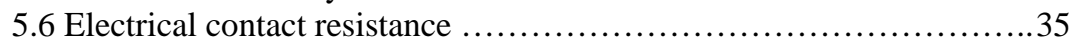

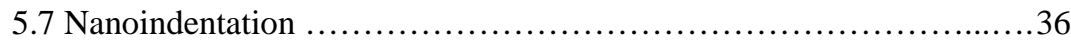

6 Electron-beam-induced crystallization ................................ 39

6.1 Radiation damage processes ........................................ 39

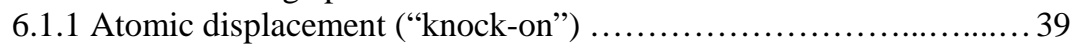

6.1.2 Specimen heating .................................................. 41 
6.1 .3 Radiolysis .................................................... 42

6.2 Viewing non-stable samples ................................. 42

6.2.1 The as-deposited state ....................................... 42

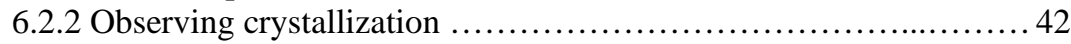

7 Summary and contribution to the field ...........................45

$7.1 \mathrm{Nb}-\mathrm{C}$ as electrical contact material .............................. 45

7.2 Ternary systems ............................................... 46

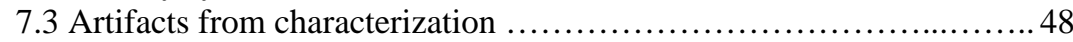

Paper 1 ..................................................................... 51

Paper 2 ............................................................. 59

Paper 3 ................................................................ 73

Paper 4 ............................................................... 83

Paper 5 .............................................................91

Paper 6 .................................................................... 105 


\section{Introduction}

\subsection{Background to my work}

Thin films ${ }^{\dagger}$ are deposited onto a substrate to enhance or add properties to the combined material system. Depending on the intended use, the thickness of the films can range from a few atomic layers to several micrometers. Thin films can be used for purely decorative purposes as in the case of earliest known use where the Egyptians hammered gold into leaves with a thickness below $1 \mu \mathrm{m}$ [1]. However, combining different substrate and thin film materials gives the opportunity to tailor also other system properties. Today, thin films are therefore wide spread and used for a large variety of purposes. For example, there are antireflective coatings for eyeglasses and hard coatings to increase the wear-resistance of cutting tools.

Coatings are also often used in electrical contact applications [2-7]. This is done mainly to protect the contact from oxidation and to lower the contact resistance. Two common materials for contact applications are the noble metals $\mathrm{Au}$ and $\mathrm{Ag}$ [8,9]. Au has a good oxidation resistance, but is expensive. Ag is less expensive, but tends to tarnish in the presence of sulfides or chlorides [10,11]. It is therefore motivated to replace noble metals with other coatings.

An interesting class of materials in this aspect is multicomponent transition metal carbides [6,12-15]. When deposited at low process temperatures, these materials tend to form nanocomposites, which consist of at least two phases, segregated on the nanoscale. Two well-studied examples are the Ti-C and Ti-Si-C systems which have already been shown to have promising electrical $[13,16,17]$ and tribological [18-20] properties. These properties are controlled by the microstructure and the material can therefore be tailored by the choice of composition and deposition conditions [20-22].

Although both the tribological and electrical properties of Ti-Si-C-based nanocomposites have already been investigated, information on how $\mathrm{Si}$ is incorporated

\footnotetext{
Sometimes the word coating is also used in the field. In some contexts this word is used for thin films thicker than $\sim 1 \mu \mathrm{m}$. In other contexts the word coating is used for all deliberately added layers, while films are referring to thin layers of contamination. In this thesis both the terms coating and thin film are used for deliberately deposited layers.
} 
in the $\mathrm{NaCl}$-structure $\mathrm{TiC}_{\mathrm{x}}$ phase has been lacking. I have therefore aimed for deeper understanding of this by investigating a model system of epitaxial $\mathrm{TiC}_{\mathrm{x}}$. The model system also shows how $\mathrm{Si}$ segregates to form a composite material at low temperatures. Also other transition metal carbides have been studied. In the case of $\mathrm{Nb}-\mathrm{C}$, the system was screened and by Lewin [23] and proposed as a candidate for electrical contact applications. Here, I investigate the system in more detail with respect to microstructure as well as electrical and mechanical properties. I find that it is at least as good as the Ti-C system for electrical contact applications.

The addition of a Si does not only add to the complexity of the system, but also allow further possibilities to tailor the properties. Results from the $\mathrm{Zr}-\mathrm{Si}$-C system show that the hardness of the films is related to the amount of $\mathrm{Si}-\mathrm{C}$ bonds and that amorphous films form for $\mathrm{Si}$ contents larger than 15 at.\% [24]. Since sputterdeposited films in the $\mathrm{Nb}-\mathrm{Si}-\mathrm{C}$ system have not been studied earlier I here investigate this system and compare the results with the $\mathrm{Zr}-\mathrm{Si}-\mathrm{C}$ system in order to separate the effects of $\mathrm{Si}$ and choice of transition metal.

Lauridsen et al. [14] investigated different A-elements $(\mathrm{A}=\mathrm{Si}, \mathrm{Ge}$ or $\mathrm{Sn})$ in Ti-A-C-Ag coatings for electrical contact applications. The results show that $\mathrm{Ge}$ gave a dense structure and the lowest contact resistance among the investigated coatings. In combination with our promising results for the $\mathrm{Nb}-\mathrm{C}$ system as electrical contact I therefore investigated the $\mathrm{Nb}-\mathrm{Ge}-\mathrm{C}$ material system. Since I also want to compare the system with some of our results for the $\mathrm{Nb}-\mathrm{Si}-\mathrm{C}, \mathrm{I}$ increased the $\mathrm{Ge}$ content up to 30 at.\%. My $\mathrm{Nb}-\mathrm{Ge}-\mathrm{C}$ coatings are, however, porous, which is not a good condition if they are going to be used in a corrosive environment.

Many of the findings of my work are related to the film microstructure as determined by high resolution transmission electron microscopy (TEM). In TEM investigations artifacts can be induced by both sample preparation and imaging [25-27]. While carefully performed sample preparation techniques can be used to obtain electron transparent samples for my samples without introducing artifacts, electron-beam-induced damage, however, proved a challenge. I found that amorphous $\mathrm{Nb}-\mathrm{Si}-\mathrm{C}$ coatings crystallize under electron beam irradiation. Therefore, I developed a method with indicated times allowed to record images of the pristine amorphous structure, and also to monitor the electron-beam-induced crystallization as well as to describe the mechanisms behind it. I also added the related $\mathrm{Zr}-\mathrm{Si}-\mathrm{C}$ system to see how the crystallization is related to the choice of transition metal.

\subsection{Objective}

The aim of my work is to relate the properties of transition metal carbides to the structure and composition of the materials. The main focus has been on material systems that have potential for electric contact application. In some cases, however, the compositional range have been extended beyond what is useful for 
electrical contacts in order to further investigate, for example, how mechanical properties is related in amorphous structures.

A second aim has been to investigate and explain the electron-beam-induced crystallization in the amorphous phase of these materials.

\subsection{Outline}

I have chosen to divide the part prior to my papers into 7 chapters, which treat different aspects of my work. The next chapter gives an introduction to electrical contacts. Chapter 3, in more detail describes the different investigated material systems together with the different microstructures observed from compositional changes. For all thin films, I have used a deposition technique called magnetron sputtering. The physics behind this method together with the special conditions required for it to work are described in chapter 4 . Chapter 5 treats some of the used characterization methods. Since a key contribution of my work is to characterize electron-beam-induced crystallization in amorphous materials, I extensively describe this phenomenon in chapter 6. Finally I summarize my contribution to the field in chapter 7 .

\section{References}

[1] M. Ohring, Materials science of thin films, $\mathbf{2}^{\text {nd }}$ ed., Academic Press, (2002)

[2] M. Grandin, U. Wiklund, Friction, wear and tribofilm formation on electrical contact materials in reciprocating sliding against silver-graphite, Wear 302 (2013) 1481-1491

[3] G. Rolland, P. Sallamand, V. Guipont, M. Jeandin, E. Boller, C. Bourda, Damage study of cold-sprayed composite materials for application to electrical contacts, $J$. Therm. Spray Technol. 21 (2012) 758-772

[4] P. W. Lees, D. W. M. Williams, Fretting behavior of gold flashed palladium, palladium nickel and palladium silver contact materials, (37th IEEE Holm Conference on Electrical Contacts, 1992)

[5] S. Umemura, K. Yasuda, T. Aoki, Contact resistance characteristics of noble metal alloys for connector contacts, IEEE Trans. Compon., Hybrids, Manuf. Technol. 14 (1991) 181-186

[6] P. Eklund, J. Emmerlich, H. Högberg, O. Wilhelmsson, P. Isberg, J. Birch, P. O. A Persson, U. Jansson, L. Hultman, Structural, electrical, and mechanical properties of nc-TiC/a-SiC nanocomposite thin films, J. Vac. Sci. Technol., B 23 (2005) 2486-2495

[7] M. Antler, Tribology of metal coatings for electrical contacts, Thin Solid Films 84 (1981) 245-256

[8] M. Braunovic, Electrical contacts - fundamentals, applications and technology, CRC Press, (2006)

[9] M. Antler, Research on gold contact materials, Gold Bull. 10 (1977) 46-47

[10] J. P. Franey, G. W. Kammlott, T. E. Graedel, The corrosion of silver by atmospheric sulfurous gases, Corros. Sci. 25 (1985) 133-143 
[11] W. Rieder, Electrical contacts - An introduction to their physics and applications, IEEE, (2005)

[12] A. Öberg, A. Kassman, B. André, U. Wiklund, M. Lindquist, E. Lewin, U. Jansson, H. Högberg, T. Joelsson, H. Ljungcrantz, Conductive nanocomposite ceramics as

tribological and electrical contact materials, Eur. Phys. J.: Appl. Phys. 49 (2010) 22902

[13] E. Lewin, E. Olsson, B. André, T. Joelsson, Å Öberg, U. Wiklund, H. Ljungcrantz, U. Jansson, Industrialisation study of nanocomposite nc-TiC/a-C coatings for electrical contact applications, Plasma Processes Polym. 6 (2009) 928-934.

[14] J. Lauridsen, P. Eklund, J. Jensen, A. Furlan, A. Flink, A. M. Andersson, U. Jansson, L. Hultman, Effects of A-elements $(\mathrm{A}=\mathrm{Si}$, Ge or $\mathrm{Sn})$ on the structure and electrical contact properties of Ti-A-C-Ag nanocomposites, Thin Solid Films 520 (2012) 51285136

[15] N. G. Sarius, J. Lauridsen, E. Lewin, U. Jansson, H. Högberg, Å Öberg, G. Sarova, G. Staperfeld, P. Leisner, P. Eklund, L. Hultman, Contact resistance of Ti-Si-C-Ag and TiSi-C-Ag-Pd nanocomposite coatings, J. Electron. Mater. 41 (2012) 560-567

[16] P. Eklund, Novel ceramic Ti-Si-C nanocomposite coatings for electrical contact applications, Surf. Eng. 23 (2007) 406-411

[17] E. Lewin, O. Wilhelmsson, U. Jansson, Nanocomposite nc-TiC/a-C thin films for electrical contact applications, J. Appl. Phys. 100 (2006) 054303

[18] T. Zehnder, J. Matthey, P. Schwaller, A. Klein, P. A. Steinmann, J. Patscheider, Wear protective coatings consisting of $\mathrm{TiC}-\mathrm{SiC}$-a-C: $\mathrm{H}$ deposited by magnetron sputtering, Surf. Coat. Technol. 163-164 (2003) 238-244

[19] M. Rester, J. Neidhardt, P. Eklund, J. Emmerlich, H. Ljungcrantz, L. Hultman, C. Mitterer, Annealing studies of nanocomposite Ti-Si-C thin films with respect to phase stability and tribological performance, Mater. Sci. Eng., A 429 (2006) 90-95

[20] D. Munteanu, C. Ionescu, C. Olteanu, A. Munteanu, F. Davin, L. Cunha, C. Moura, F. Vaz, Influence of composition and structural properties in the tribological behaviour of magnetron sputtered Ti-Si-C nanostructured thin films, prepared at low temperature, Wear 268 (2010) 552-557

[21] J. Lauridsen, P. Eklund, T. Joelsson, H. Ljungcrantz, Å Öberg, E. Lewin, U. Jansson, M. Beckers, H. Högberg, L. Hultman, High-rate deposition of amorphous and nanocomposite Ti-Si-C multifunctional coatings, Surf. Coat. Technol. 205 (2010) 299305

[22] J. E. Krzanowski, S. H. Koutzaki, Mechanical Properties of Sputter-Deposited Titanium-Silicon-Carbon Films, J. Am. Ceram. Soc. 84 (2001) 672-674

[23] E. Lewin, Design of carbide-based nanocomposite coatings, PhD Thesis, Acta Universitatis Upsaliensis, (2009)

[24] M. Andersson, S. Urbonaite, E. Lewin, U. Jansson, Magnetron sputtering of Zr-Si-C thin films, Thin Solid Films 520 (2012) 6375-6381

[25] R. F. Egerton, P. Li, M. Malac, Radiation damage in the TEM and SEM, Micron 35 (2004) 399-409.

[26] J. P. McCaffrey, Small-angle cleavage of semiconductors for transmission electron microscopy, Ultramicroscopy 38 (1991) 149-157

[27] D. B. Williams, C. B. Carter, Transmission Electron Microscopy: A Textbook for Materials Science, $2^{\text {nd }}$ ed., Springer, (2009) 


\section{Electrical contacts}

Electrical contacts are of importance for this thesis since my collaboration with the industrial partners in the VINNEX Center FunMat Theme 1 deals with the development of coatings ${ }^{\dagger}$ for electrical contact applications. This is reflected in Papers 1 and 6, where we investigate how the microstructure influences electrical properties of $\mathrm{Nb}-\mathrm{C}$ and $\mathrm{Nb}-\mathrm{Ge}-\mathrm{C}$ coatings, respectively. The following chapter gives a brief introduction to the function of electric contacts and available contact materials. More detailed description of electrical contact theory can be found, e.g., in texts written by Holm [1], Slade [2], and Braunovic [3].
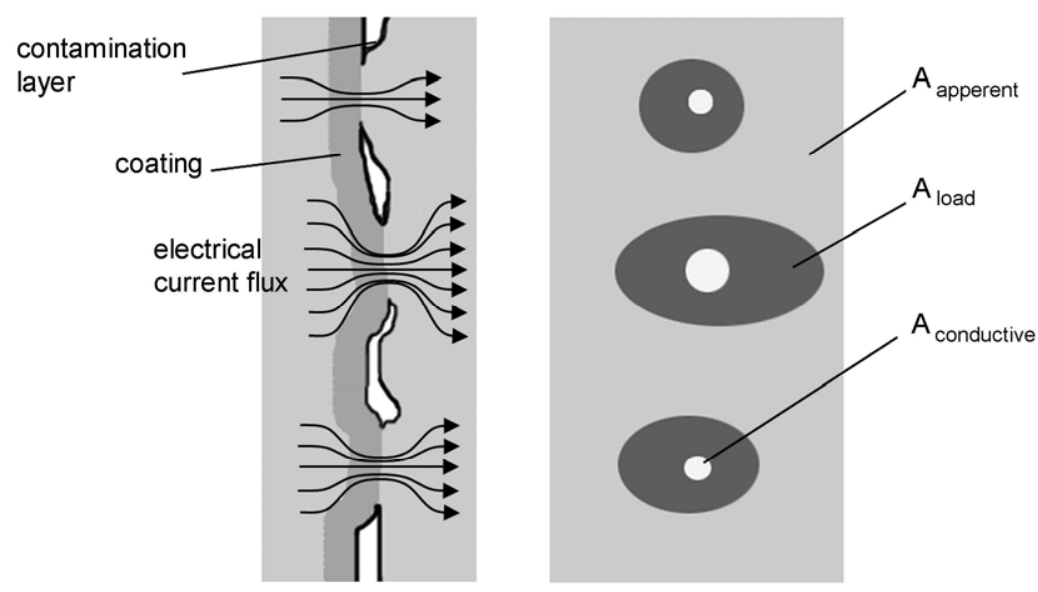

Fig. 2.1 Schematic figure of the cross-section (left) and plan view (right) of an electrical contact. (After Lewin [4])

An electrical contact is according to the definition by Holm [1] "a releasable junction between two conductors which is apt to carry electric current". This means two surfaces (contact members) that when in contact with each other are able to carry electrons from one of the contact members (cathode) to the other

\footnotetext{
${ }^{\dagger}$ Note that in the field of electrical contacts the terms film or thin film is often referring to a contamination layer formed on top of the contact. To avoid confusion these terms are not used in this chapter.
} 
contact member (anode). However, the surface interaction between the contact members can be very complex. This is illustrated in Fig. 2.1, which shows schematic figures of an electrical contact in cross-section (left), and plan-view (right). This contact consists of one coated and one uncoated part, which are pressed together by a contact force. Although the apparent contact area, $\mathrm{A}_{\text {apparent }}$, may seem large, surface roughness will reduce the actual load bearing area, $A_{\text {load }}$, where an electric current can flow. If the materials also include non-conducting phases, e.g., an insulating oxide on the surface, the actual conductive area,

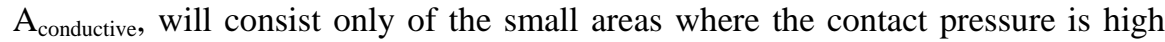
enough to break through the oxide. The conducting spots out of which $\mathrm{A}_{\text {conductive }}$ consists are called a-spots. At an a-spot the electrical current flux is much higher than in the bulk of the contact. This gives rise to a constriction resistance in the contact. The total constriction depends on the area and distribution of the a-spots. The contact resistance, which is an important property of all electrical contacts, is mainly caused by the constriction resistance. Therefore the contact resistance is not only a property of the contact material, but also of the application (e.g., force applied) and surface contamination.

Electrical contacts are found in all electrical systems. The requirements on these contacts are different depending on in which regime they are supposed to work, e.g., at high or low contact force, and how their mechanism is designed, e.g., sliding or permanent contact. Except for being a good electrical conductor and having a low contact resistance, contact materials also have to be corrosion resistant and ductile. In this thesis possible applications for the investigated material systems, $\mathrm{Nb}-\mathrm{C}$ and $\mathrm{Ti}-\mathrm{Si}-\mathrm{C}$, involve non-static contacts. This adds wear resistance and low friction to already mentioned properties.

The electrical and mechanical properties of the top surface are often the most crucial part in electrical contacts. A contaminated surface will increase the contact resistance and reduce performance of the contact. Therefore, contacts are often coated. Not only the functionality of the coating is of importance, but also the adhesion to the substrate, the cost, and the environmental impact of the deposition must be considered.

The dominant method of producing electrical contact coatings today is by plating. In electroplating metal ions are deposited onto a conductive surface from an electrolytic bath. Electroplating can be used for dense coatings. Another plating method is a chemical reduction process called electroless plating. In the process coating growth will occur on a activated surface immersed in the plating solution. Both methods can be used for complex shapes. However, there are limitations for which materials and compositions that can be used. There is also an environmental issue with dangerous chemicals from the plating bath.

An alternative method that is used for the coatings presented in this thesis is physical vapor deposition, PVD (see Ch. 4 for a more detailed description of this method). The main advantage over plating is that a much wider range of materials and compositions can be deposited. PVD is also a more flexible technique for 
changing between different coating materials in the deposition system and is more environmental friendly. One disadvantage is that the method is non-selective, which means that the coating material will be deposited also on, e.g., the chamber walls. This can result in a waste of expensive coating materials.

As substrate material for electrical contact coatings $\mathrm{Cu}$-based alloys are often used, e.g., brass or bronze. $\mathrm{Cu}$ is used since it is relatively inexpensive and at the same time has very good electrical and thermal conductivity. The drawback is a relatively low deformation temperature $\left(200-300{ }^{\circ} \mathrm{C}\right)$ [3]. A diffusion barrier of $\mathrm{Ni}$ is often used to hinder the $\mathrm{Cu}$ from diffusing through the top coating and to serve as load support. The top coating is often a noble metal or alloy in order for the contact resistance to remain low and stable over the lifetime of the contact. An alternative to $\mathrm{Cu}$-based alloys is stainless steel, which is cheaper than $\mathrm{Cu}$ and has good corrosion properties.

Among the noble metals, Au has the best resistance against oxidation, but is at the same time a very soft metal. It is therefore a very good contact material for lowcurrent and low contact force applications [5] such as mobile phones and other hand-held electronics. Adding small amounts of $\mathrm{Ni}$ and $\mathrm{Co}$ increases hardness and wear resistance. These alloys are therefore often called hard gold. The main drawback with $\mathrm{Au}$ is the high price and negative environmental impact when deposited by electro plating.

A less expensive alternative to $\mathrm{Au}$ is $\mathrm{Ag}$. $\mathrm{Ag}$ has the lowest electrical resistivity and highest thermal conductivity of all elements. However, if $\mathrm{Ag}$ is exposed to sulfides [6] or chlorides [7] it will tarnish and form a contamination layer that will decrease the performance. To protect Ag from tarnish it can be alloyed with $\mathrm{Pd}$ [8], but at a much higher production cost of the coating.

The high price of $\mathrm{Au}$ and the tarnishing of $\mathrm{Ag}$ motivate a search for new materials. In order to allow for tribological improvements and at the same time retain good electrical properties, nanocomposite materials have been investigated. Special interests have been paid to binary and ternary systems of transition metals and carbon, such as Ti-C and Ti-Si-C [9-12]. These systems often consist of metalcarbon grains in a matrix of amorphous $\mathrm{C}$. The properties can be controlled by the structure, e.g., grain size and matrix thickness, as well as the choice of metal [13-15]. Most nanocomposite coatings can be deposited at low temperatures and are therefore useful for industrial substrates such as $\mathrm{Cu}$, which softens already at $\sim 200{ }^{\circ} \mathrm{C}$ [3]. Studies to scale up the deposition process to meet industrial demands such as larger deposition areas and higher deposition rates have been successful [9-10].

However, to be able to develop new nanocomposite materials for electrical contact applications a further understanding on how the structure and composition affects the properties is needed. This is as mentioned in the beginning of this chapter done with the $\mathrm{Nb}-\mathrm{C}$ system in Paper 1, where I show how the microstructure influences electrical properties. 


\section{References}

[1] R. Holm, Electric contacts, theory and application, $4^{\text {th }}$ ed., Springer-Verlag, (1967)

[2] P.G. Slade, ed., Electrical contacts - principles and applications, CRC Press, (1999)

[3] M. Braunovic, Electrical contacts - fundamentals, applications and technology,

CRC Press, (2006)

[4] E. Lewin, Design of carbide-based nanocomposite coatings, PhD Thesis, Acta

Universitatis Upsaliensis, (2009)

[5] M. Antler, Tribology of metal coatings for electrical contacts, Thin Solid Films 84 (1981), 245-256

[6] J.P. Franey, G.W. Kammlott, T.E. Graedel, The corrosion of silver by atmospheric sulfurous gases, Corros. Sci. 25 (1985), 133-143

[7] W. Rieder, Electrical contacts - An introduction to their physics and applications, IEEE, (2005)

[8], M. Doriot-Werlé, O. Banakh, P.-A. Gay, J. Matthey, P.-A. Steinmann, Tarnishing resistance of silver-palladium thin films, Surf. Coat. Technol. 200 (2006) 6696-6701

[9] E. Lewin, E. Olsson, B. André, T. Joelsson, Å. Öberg, U. Wiklund, H. Ljungcrantz, U. Jansson, Industrialisation study of nanocomposite nc-TiC/a-C coatings for electrical contact applications, Plasma Processes and Polym. 6 (2009) 928-934

[10] J. Lauridsen, P. Eklund, T. Joelsson, H. Ljungcrantz, Å. Öberg, E. Lewin, U. Jansson, M. Beckers, H. Högberg, L. Hultman, High-rate deposition of amorphous and nanocomposite Ti-Si-C multifunctional coatings, Surf. Coat. Technol. 205 (2010) 299_ 305

[11] Å. Öberg, Å. Kassman, B. André, U. Wiklund, M. Lindquist, E. Lewin, U. Jansson, H. Högberg, T. Joelsson, H. Ljungcrantz, Conductive nanocomposite ceramics as tribological and electrical contact materials, Eur. Phys. J.: Appl. Phys. 49, (2010) 22902 [12] P. Eklund, J. Emmerlich, H. Högberg, O. Wilhelmsson, P. Isberg, J. Birch, P.O.A. Persson, U. Jansson, L. Hultman, Structural, electrical, and mechanical properties of nc-TiC/a-SiC nanocomposite thin films, J. Vac. Sci. Technol., B 23 (2005) 2486-2495 [13] D. Munteanu et al., Influence of composition and structural properties in the tribological behaviour of magnetron sputtered Ti-Si-C nanostructured thin films, prepared at low temperature, Wear 268 (2010) 552-557

[14] M. Andersson, S. Urbonaite, E. Lewin, U. Jansson, Magnetron sputtering of Zr-SiC thin films, Thin Solid Films 520 (2012) 6375-6381

[15] J. E. Krzanowski, J. Wormwood, Microstructure and mechanical properties of Mo$\mathrm{Si}-\mathrm{C}$ and $\mathrm{Zr}-\mathrm{Si}-\mathrm{C}$ thin films: Compositional routes for film densification and hardness enhancement, Surf. Coat. Technol. 201 (2006) 2942-2952 


\section{Material systems}

In this thesis, the studied materials are carbides based on a transition metal (Me) from group $4(\mathrm{Ti}$ and $\mathrm{Zr}$ ) or group $5(\mathrm{Nb})$ in the periodic table (see Fig. 3.1). In most of the included papers also $\mathrm{Si}$ or Ge have been added. This chapter starts with a section explaining different microstructures observed in this thesis followed by three sections describing compositional effects in the Me-C, Me-Si-C, and Me-Ge-C systems, respectively.

\begin{tabular}{|c|c|c|c|c|c|c|c|c|c|c|c|c|c|c|c|c|c|}
\hline $\begin{array}{l}\mid \mathrm{A} \\
1 \\
\mathrm{H}\end{array}$ & $\| A$ & & & & & & & & & & & IIIA & IVA & VA & VIA & VIIA & $\begin{array}{c}\text { VIIIA } \\
2 \\
\mathrm{He}\end{array}$ \\
\hline $\begin{array}{c}3 \\
\mathrm{Li}\end{array}$ & $\begin{array}{c}4 \\
\mathrm{Be}\end{array}$ & & & & & & & & & & & $\begin{array}{l}5 \\
B\end{array}$ & $\frac{1 V A}{6}$ & $\begin{array}{c}\mathrm{V} \\
\mathrm{N}\end{array}$ & $\begin{array}{l}8 \\
0\end{array}$ & \begin{tabular}{|c|}
9 \\
$F$
\end{tabular} & $\begin{array}{l}10 \\
\mathrm{Ne}\end{array}$ \\
\hline $\begin{array}{l}11 \\
\mathrm{Na}\end{array}$ & $\begin{array}{l}12 \\
\mathrm{Mg}\end{array}$ & IIIB & IVB & VB & VIB & VIIB & & -VII & & IB & $\mathrm{IIB}$ & $\begin{array}{l}13 \\
\mathrm{Al}\end{array}$ & $\begin{array}{l}14 \\
\mathrm{Si}\end{array}$ & $\begin{array}{c}15 \\
P\end{array}$ & $\begin{array}{r}16 \\
S\end{array}$ & $\begin{array}{c}17 \\
\mathrm{Cl}\end{array}$ & $\begin{array}{c}18 \\
\mathrm{Ar}\end{array}$ \\
\hline $\begin{array}{c}19 \\
\mathrm{~K}\end{array}$ & $\begin{array}{l}20 \\
\mathrm{Ca}\end{array}$ & $\begin{array}{l}21 \\
\text { Sc }\end{array}$ & $\begin{array}{l}22 \\
\mathrm{Ti}\end{array}$ & $\begin{array}{l}23 \\
\mathrm{~V}\end{array}$ & $\begin{array}{l}24 \\
\mathrm{Cr}\end{array}$ & $\begin{array}{l}25 \\
\mathrm{Mn}\end{array}$ & $\begin{array}{l}26 \\
\mathrm{Fe}\end{array}$ & $\begin{array}{l}27 \\
\text { Co }\end{array}$ & $\begin{array}{l}28 \\
\mathrm{Ni}\end{array}$ & $\begin{array}{l}29 \\
\mathrm{Cu}\end{array}$ & $\begin{array}{l}30 \\
\mathrm{Zn}\end{array}$ & $\begin{array}{l}31 \\
\mathrm{Ga}\end{array}$ & $\begin{array}{l}32 \\
\mathrm{Ge}\end{array}$ & $\begin{array}{l}33 \\
\text { As }\end{array}$ & $\begin{array}{l}34 \\
\mathrm{Se}\end{array}$ & $\begin{array}{l}35 \\
\mathrm{Br}\end{array}$ & $\begin{array}{l}36 \\
\mathrm{Kr}\end{array}$ \\
\hline $\begin{array}{l}37 \\
\mathrm{Rb}\end{array}$ & $\begin{array}{l}38 \\
\mathrm{Sr}\end{array}$ & $\begin{array}{c}39 \\
Y\end{array}$ & $\begin{array}{l}40 \\
\mathrm{Zr}\end{array}$ & $\begin{array}{l}41 \\
\mathrm{Nb}\end{array}$ & $\begin{array}{l}42 \\
\text { Mo }\end{array}$ & $\begin{array}{l}43 \\
\text { Tc }\end{array}$ & $\begin{array}{l}44 \\
\mathrm{Ru}\end{array}$ & $\begin{array}{l}45 \\
\mathrm{Rh}\end{array}$ & $\begin{array}{r}46 \\
P d\end{array}$ & $\begin{array}{l}47 \\
\mathrm{Ag}\end{array}$ & $\begin{array}{l}48 \\
\mathrm{Cd}\end{array}$ & $\begin{array}{l}49 \\
\text { In }\end{array}$ & $\begin{array}{l}50 \\
\mathrm{Sn}\end{array}$ & $\begin{array}{l}51 \\
\mathrm{Sb}\end{array}$ & $\begin{array}{l}52 \\
\mathrm{Te}\end{array}$ & $\begin{array}{c}53 \\
1\end{array}$ & $\begin{array}{l}54 \\
X e\end{array}$ \\
\hline $\begin{array}{l}55 \\
\text { Cs }\end{array}$ & $\begin{array}{c}56 \\
\mathrm{Ba}\end{array}$ & $\begin{array}{l}57 \\
\text { La }\end{array}$ & $\begin{array}{l}72 \\
\mathrm{Hf}\end{array}$ & $\begin{array}{l}73 \\
\mathrm{Ta}\end{array}$ & $\begin{array}{l}74 \\
\text { W }\end{array}$ & $\begin{array}{c}75 \\
\mathrm{Re}\end{array}$ & $\begin{array}{l}76 \\
\text { Os }\end{array}$ & $\begin{array}{l}77 \\
\mathrm{Ir}\end{array}$ & $\begin{array}{l}78 \\
\mathrm{Pt}\end{array}$ & $\begin{array}{l}79 \\
\mathrm{Au}\end{array}$ & $\begin{array}{l}80 \\
\mathrm{Hg}\end{array}$ & $\begin{array}{l}81 \\
\mathrm{TI}\end{array}$ & $\begin{array}{l}82 \\
\mathrm{~Pb}\end{array}$ & $\begin{array}{l}83 \\
\mathrm{Bi}\end{array}$ & $\begin{array}{l}84 \\
\text { Po }\end{array}$ & $\begin{array}{l}85 \\
\text { At }\end{array}$ & $\begin{array}{r}86 \\
\mathrm{Rn}\end{array}$ \\
\hline
\end{tabular}

Fig. 3.1 Carbide materials based on the marked elements of the periodic table are studied in this thesis

\subsection{Microstructures}

The microstructures observed for the films in this thesis are represented in Fig. 3.2 and range from epitaxial TiC (Paper 2), through composites of Ti-Si-C, Nb-Ge-C and $\mathrm{Nb}-\mathrm{Si}-\mathrm{C}$ and (Paper 1-3, 6), to amorphous $\mathrm{Nb}-\mathrm{Si}-\mathrm{C}$ and $\mathrm{Zr}-\mathrm{Si}-\mathrm{C}$ (Paper 4, 5). Since the deposition conditions are almost the same for all investigated thin films the variations in microstructure are mainly due to compositional changes.

An epitaxial material is in a single-crystal state grown with a lattice orientational relationship to the substrate. The epitaxy can preferably be analyzed using pole figures (Section 5.2.2) or electron diffraction (Section 5.1.1) and is described by indicating one common plane (()-brackets) and one common direction ([]-brackets) for the film and substrate. In the case of $\mathrm{TiC}$ on $\mathrm{Al}_{2} \mathrm{O}_{3}(0001)$ as in Paper 2, this means $\mathrm{TiC}(111) / / \mathrm{Al}_{2} \mathrm{O}_{3}(0001)$ and $\mathrm{TiC}[01 \overline{1}] / / \mathrm{Al}_{2} \mathrm{O}_{3}[1 \overline{1} 00]$ as seen in the TEM image in Fig. 3.2a). However, if a larger area of the sample is viewed also $\mathrm{TiC}[0 \overline{1} 1] / / \mathrm{Al} 2 \mathrm{O} 3[1 \overline{1} 00]$ is possible depending on the stacking sequence of $\mathrm{TiC}(111)$. This means that the TiC film will consist of two domains rotated $180^{\circ}$ with respect to each other and with common (111) planes parallel to the surface. In the electron diffraction pattern in Fig. 3.2a) the two different domains have 
been indexed 1 and 2 and the mirror plane is drawn by a vertical dotted line. The substrate pattern is not included in this figure.

The word composite means that the material consists of at least two phases. Each phase can be amorphous or crystalline and consist of one or more elements. Fig. 3.2 b) shows an example taken from Paper 2 of a sample from the Ti-Si-C system, where crystalline $\mathrm{TiC}$ grains are embedded in a matrix of amorphous $\mathrm{C}$ and $\mathrm{SiC}$. This is often written as c-TiC/a-C/a-SiC. To emphasize that the size of the crystalline $\mathrm{TiC}$ grains are smaller than $100 \mathrm{~nm}$ in one or more dimensions (i.e. are nano-crystalline [1]) "nc-" is added to $\mathrm{TiC}$ so it now reads nc-TiC/a-C/a-SiC. In the same way a system is called a nanocomposite when one or more of its phases are restricted to a size less than $100 \mathrm{~nm}$ in at least one dimension.
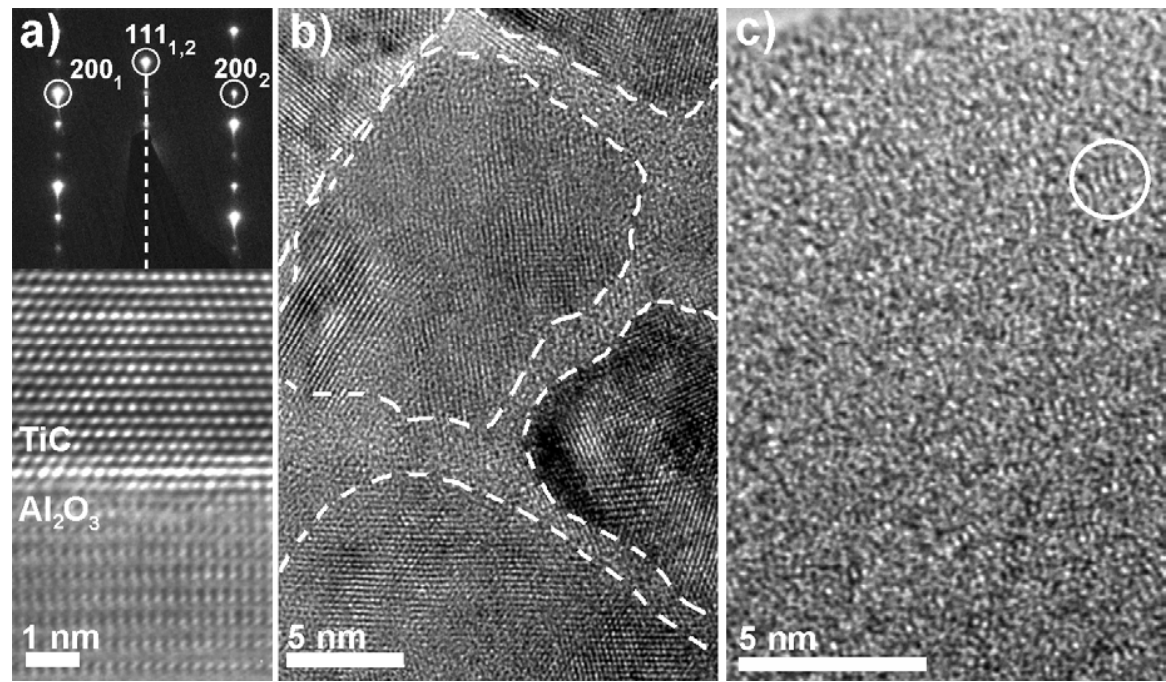

Fig 3.2 Different observed microstructures a) epitaxial, b) composite, and c) amorphous.

By definition the atoms in an amorphous material are distributed without any long range order between them as shown in Fig. 3.2 c). In practice the interpretation of an amorphous material is often more unclear. With X-ray amorphous we mean a material, which does not give any or very broad peaks in such diffraction measurements. However, these materials can still contain crystalline grains of the order of a few nanometers. Even when viewed in high resolution TEM there can be a problem to distinguish between amorphous and nanocrystalline materials since also the former material type can have a short-range order [2]. An example of this kind of short range order is marked with a circle in Fig. 3.2c). In Paper 4 and 5 I consider materials with crystalline particles larger than $\sim 1.5 \mathrm{~nm}$ to be nanocrystalline and materials with areas with short-range order smaller than this amorphous. 


\section{$3.2 \mathrm{Me}-\mathrm{C}$}

The metal carbides studied in this thesis belong to the refractory carbides. They all share properties like high hardness and high melting point together with semimetallic electrical conductivity [3]. Hägg formulated an empirical rule for the formation of interstitial carbides [4]. The rule states that if the atomic radii carbonto-metal ratio is smaller than 0.59 interstitial carbides form where carbon occupies the largest interstitial sites in the metal crystal structure. The difference between an interstitial carbide and a solid solution is that the metal crystal structure changes when forming an interstitial carbide while the structure remains the same if carbon is dissolved interstitially and form an solid solution. The structure of the interstitial carbides results in a combination of ionic, covalent and metallic bonds [5].

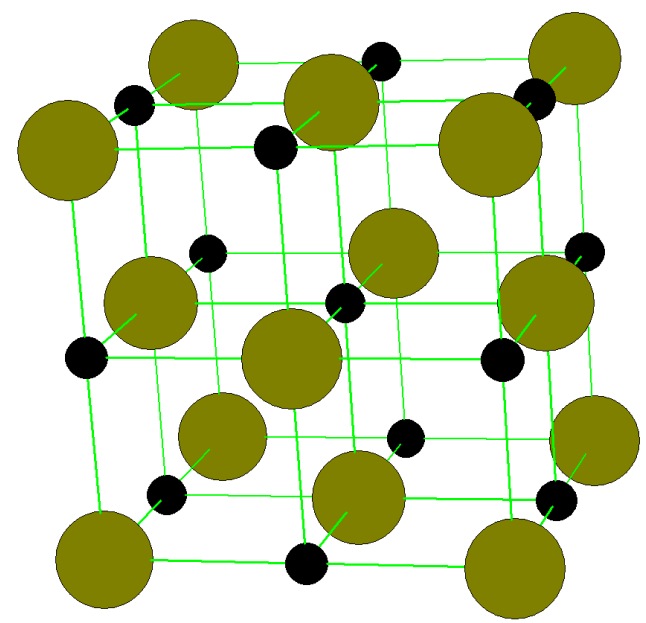

Fig. 3.3 Structure of the metal carbides in this thesis. Smaller atoms are $C$ located at the interstitial octahedral sites of the Me fcc lattice.

All metals studied in this thesis fulfill the Hägg rule [4] and form carbides in the $\mathrm{NaCl}$ (B1) structures as shown in Fig. 3.3 with $\mathrm{C}$ at the interstitial octrahedral sites of the Me fcc lattice. For $\mathrm{Ti}$ and $\mathrm{Zr}$, this is the only carbide phase, while for $\mathrm{Nb}$ there also exists an $\mathrm{Nb}_{2} \mathrm{C}^{\dagger}$ phase [4].

The $\mathrm{B} 1$ phases can be non-stoichiometric and therefore often written as $\mathrm{MeC}_{\mathrm{x}}$, where $\mathrm{x}$ is the carbon to metal ratio. The stability range is wide with $0.47-0.97$ [7], $0.72<\mathrm{x}<1.0$ [4], and $0.61<\mathrm{x}<1.0$ [8], for $\mathrm{Ti}, \mathrm{Nb}$, and $\mathrm{Zr}$, respectively. The carbon content has a large influence on the lattice parameter [6], which changes parabolically. The smallest value for the lattice parameter is found at the lowest value of $\mathrm{x}$ in the stability range. For the $\mathrm{Zr}$ and $\mathrm{Ti}$ carbides, the largest lattice parameter is, however, not at maximum $\mathrm{x}$.

\footnotetext{
$\dagger$ This phase has a narrow range of existence at low temperatures [6], and probably due to the relatively high carbon content in my films, it was never observed in this thesis.
} 
With increasing carbon content the excess $\mathrm{C}$ starts to form an amorphous phase turning the $\mathrm{MeC}$ system into a two-phase system of $\mathrm{nc}^{-} \mathrm{MeC}_{\mathrm{x}} / \mathrm{a}-\mathrm{C}$. This is possible even before $\mathrm{x}$ reaches its maximum value. $\mathrm{In}_{\mathrm{TiC}}$ for example, an a-C phase starts to form already around $\mathrm{x}>0.7[4,5]$. When epitaxial TiC films are grown in Paper 2 we therefore try to keep $\mathrm{x}$ below this value. Even higher carbon content reduces the grain size further and the amount of a-C matrix increases.

Not only the structure, but also mechanical and electrical properties change with the $\mathrm{C}$ content. The properties are affected by both the understoichiometry and the amount of free carbon. The carbon vacancies in the $\mathrm{MeC}_{\mathrm{x}}$ will lead to higher amounts of electron scattering which increases the electrical resistivity with smaller $\mathrm{x}[3,9]$. At the same time loss of strong covalent bonds decreases the hardness of the material with decreasing $\mathrm{x}$ [3]. For the $\mathrm{nc}^{-} \mathrm{MeC}_{\mathrm{x}} / \mathrm{a}-\mathrm{C}$ nanocomposite, increasing carbon content can at first increase the hardness due to the formation of smaller grains. The a-C matrix is in itself, however, softer than the $\mathrm{MeC}_{\mathrm{x}}$ grains. Hence, with even higher carbon content a thicker matrix soften the coating by its presence and the fact that the grains can glide and rotate to a larger extent. Since the amorphous matrix does not conduct an electrical current as well as the $\mathrm{MeC}_{\mathrm{x}}$ grains, the electrical resistivity is increased with increased amount of a-C. The resistivity is in this case also increased by a larger amount of grain boundary scattering of electrons due to the formation of smaller $\mathrm{MeC}_{\mathrm{x}}$ grains.

Paper 1 describes the effect of the $\mathrm{C} / \mathrm{Nb}$ ratio in $\mathrm{NbC}$ nanocomposite films. The $\mathrm{NbC}$ system was selected on the basis of preliminary results from Lewin, [10] who studied several different $\mathrm{MeC}$ intended for electrical contact application, and found $\mathrm{NbC}$ as a possible candidate. The results are compared to $\mathrm{TiC}$ nanocomposites with the same composition since this material previously has shown interesting results as electrical contact material [11,12]. Smaller grains and less free carbon in the $\mathrm{NbC}$ system for a given $\mathrm{C} / \mathrm{Me}$ ratio, give a thinner amorphous matrix and a higher value of $\mathrm{x}$ in the $\mathrm{MeC}_{\mathrm{x}}$. This leads to contact properties of the $\mathrm{Nb}-\mathrm{C}$ composite that are at least as good or better as Ti-C.

\subsection{Me-Si-C}

The complexity of the binary metal carbide system increases substantially at the addition of a third element. Depending on the composition, temperature, and type of growth template the structure of the Me-Si-C materials can form a solid solution, two- or multiphase materials, nanocomposite, amorphous, or nanolaminate structures (see below). Since the properties and the structure depend to large extent on both $\mathrm{Si}$ and $\mathrm{C}$ content [13-15], also the ability to design and combine several different desired properties into a multifunctional material increases for the ternary system. Early transition metal silicon carbide thin films have therefore been studied for use in a wide range of different applications such as protective coatings [16-18], electrical contacts [19], solar cells [20], and thermal printing heads [21]. 
One reason to consider the $\mathrm{Me}-\mathrm{Si}-\mathrm{C}$ systems is the possibility of forming so called MAX phases. By a broader definition MAX phases are a group of inherently nanolaminated materials consisting of an early transition metal (M), a group A element and either C and/or N (X) [22]. This class of materials has been reported to have an interesting combination of metallic and ceramic properties [23]. Of the different $\mathrm{Me}-\mathrm{Si}-\mathrm{C}$ systems investigated in this thesis it is $\mathrm{Ti}-\mathrm{Si}-\mathrm{C}$ that has been reported to form a MAX phase $\left(\mathrm{Ti}_{3} \mathrm{SiC}_{2}\right)$ [22]. This MAX-phase was measured to have good electrical and thermal conductivity, together with corrosion and heat resistance [23-26], which is of interest for electrical contact applications. Since the diffusivity of atoms needs to be high in order to form the rather large unit cell $(\sim 17.7 \AA$ c-axis $)$, high substrate temperatures $\left(>700{ }^{\circ} \mathrm{C}\right)$ are usually required in order to deposit a MAX phase structure $[19,25]$. This is problematic in some industrial processes due to the heat sensitivity of several industrially relevant substrates (e.g., steel and $\mathrm{Cu}$ ) [27]. Because of these requirements of lower deposition temperatures, I have in this thesis not been directly concerned with the MAX phase formation.

At temperatures below $700{ }^{\circ} \mathrm{C}$, cubic $\mathrm{MeC}$ are normally observed as the main crystalline phase although other phases such as metal-silicides have also been observed in XRD [25,28,29]. The solubility of $\mathrm{Si}$ in the cubic $\mathrm{MeC}_{\mathrm{x}}$ is low (less than a few at.\%) [5,30] and at higher concentrations Si therefore segregates to grain boundaries. This $\mathrm{Si}$ segregation disturbs the growth of $\mathrm{MeC}$ crystalline grains and reduces the grain size compared to the binary systems. The resulting microstructures of $\mathrm{Me}-\mathrm{Si}-\mathrm{C}$ thin films deposited by magnetron sputtering thus typically consist of nanocomposites, with nanometer sized metal carbide grains (nc-MeC) in an amorphous matrix of $\mathrm{C}$ or $\mathrm{SiC}$ (a-C/a-SiC) $[16,18,19,25,31,32]$.

Understanding how the $\mathrm{Si}$ interacts with the $\mathrm{MeC}$ and segregates to form a composite material is an important key to be able to explain the properties of the formed materials. Suggestions on the position of $\mathrm{Si}$ dissolved in $\mathrm{TiC}_{\mathrm{x}}$ have been made for both the C [33,34] and Ti [35-37] sites. In Paper 2 a model system of epitaxial $\mathrm{TiC}_{\mathrm{x}}(\mathrm{x} \sim 0.7)$ is used to investigate how low contents of $\mathrm{Si}$ is gradually incorporated in the structure. The experiments are combined with theoretical stability calculations. The results show that $\mathrm{Si}$ sits preferentially on the $\mathrm{C}$ sites in the $\mathrm{TiC}$ structure. However only a few at.\% Si can be incorporated before the epitaxy breaks down and a nanocomposite structure of nc-TiC/a-SiC is formed.

Amorphous phases can usually form at higher Si contents and at least X-ray amorphous films have been observed in several different $\mathrm{Me}-\mathrm{Si}-\mathrm{C}$ systems [15, $21,38,39]$. The amount of $\mathrm{Si}$ required to form a completely amorphous system is dependent on the metal. For $\mathrm{Zr}$, which is known for having a glass-forming ability the required Si content is $\sim 15$ at.\% for dc magnetron sputtering at $350{ }^{\circ} \mathrm{C}$ [38]. Under similar deposition conditions I found in Paper 3 that the glass transition for $\mathrm{Nb}-\mathrm{Si}-\mathrm{C}$ is 25 at.\% $\mathrm{Si}$ and from depositions of Ti-Si-C thin films I observe retained nanocrystallinity for up to 30 at.\% $\mathrm{Si}$ in $\mathrm{Ti}-\mathrm{Si}-\mathrm{C}$ thin films. However, the deposition condition also seems to be of importance. If, for example, cooled substrates [15] or a close distance between substrate and target [31] are used magnetron sputtering can result in Ti-Si-C films that are amorphous in HRTEM. 
The energetic electron irradiation during TEM studies can induce crystallization in amorphous Nb-Si-C and Zr-Si-C samples. In Paper 4 I show that displacements of atoms are the cause of this crystallization. (See more details on electron induced crystallization in Ch. 6.) Paper 5 shows that a higher Si content to a small extent can stabilize the amorphous structures against electron-beam-induced crystallization. However the largest difference in stability is due to the choice of transition metal. $\mathrm{Zr}-\mathrm{Si}-\mathrm{C}$ films are more stable than $\mathrm{Nb}-\mathrm{Si}-\mathrm{C}$ films.

As for the Me-C films of previous section compositional and structural changes result in changes of the properties. Paper 3 investigates the change in properties at different compositions in the $\mathrm{Nb}-\mathrm{Si}-\mathrm{C}$ system. Results from the $\mathrm{Zr}-\mathrm{Si}-\mathrm{C}$ system in ref. [38] were used in order to separate between the effects of Si and choice of transition metal, in comparison to my Nb-based system. That work observed direct dependence between the relative amount of strong $\mathrm{Si}-\mathrm{C}$ bonds and mechanical properties in the amorphous material [38]. In my results from the $\mathrm{Nb}-\mathrm{Si}-\mathrm{C}$ system the relation between the relative amount of $\mathrm{Si}-\mathrm{C}$ bonds and the hardness of the films is confirmed, whereas the reduced elastic modulus is affected by the choice of transition metal. These are promising results since high wear resistance depend on a high $\mathrm{H} / \mathrm{E}$ ratio [40] and such films therefore can be achieved by appropriate choice of film composition and transition metal.

\subsection{Me-Ge-C}

In sputtered Me-Ge-C films at temperatures below $400{ }^{\circ} \mathrm{C}$ the addition of $\mathrm{Ge}$ similar to the case of $\mathrm{Si}$ disturbs the growth of the Me-C leading to smaller grains [41] or even amorphization of the Me-C phase [42]. However, Ge is a weaker carbide former than $\mathrm{Si}$ and does not form carbides in thin films. Instead $\mathrm{Ge}$ agglomerates and up to $90 \%$ of the Ge content can be bonded to Ge (Paper 6). The Ge can then either be in an amorphous phase as found in Paper 6 or in an elemental crystalline phase as have been observed by X-ray diffraction for other systems [41-43].

Also, the electrical properties are affected by addition of Ge. In magnetron sputtered V-Ge-C films deposited at 300 and $400{ }^{\circ} \mathrm{C}$ a reduction of the resistivity was observed at the addition of Ge compared to the binary V-C nanocomposite, even if the cause was not totally clarified [42]. A comparison between different Aelement $(\mathrm{A}=\mathrm{Si}, \mathrm{Ge}$ or $\mathrm{Sn})$ in Ti-A-C-Ag coatings for electrical contact applications show that $\mathrm{Ge}$ gives the lowest contact resistance among the investigated coatings [41].

$\mathrm{Nb}-\mathrm{Ge}-\mathrm{C}$ is a rather unexplored material system. Spear investigated the system in the 80's by arc-melting and rapid quenching of pellets from elemental powders to determine equilibrium tie-lines between solid phases in ternary phase diagram [44]. Recently, in work related to but not included in this thesis, we predicted by theoretical calculations the stability of a previously unknown $\mathrm{Nb}_{2} \mathrm{GeC} \mathrm{MAX}$ phase, which we were also able to synthesize with magnetron sputtering [45]. 
In Paper $6 \mathrm{I}$ investigate at the structure and electrical properties of $\mathrm{Nb}-\mathrm{Ge}-\mathrm{C}$ samples deposited with magnetron sputtering at a lower deposition temperature $\left(200{ }^{\circ} \mathrm{C}\right)$.

\section{References}

[1] S. C. Tjong, H. Chen, Nanocrystalline materials and coatings, Mater. Sci. Eng., $R 45$ (2004) $1-88$

[2] A. Cavaleiro, J. T. de Hosson, Nanostructured coatings, Springer, (2006)

[3] W. S. Williams, Physics of transition metal carbides, Mater. Sci. Eng. 105-106 (1988) $1-10$

[4] L. E. Toth, Transition metal carbides and nitrides, Academic Press, (1971)

[5] U. Jansson, E. Lewin, Sputter deposition of transition-metal carbide films - A critical review from a chemical perspective, Thin Solid Films 536 (2013) 1-24

[6] E. K. Storms, The refractory carbides, Academic Press, (1967)

[7] Hugh O. Pierson, Handbook of refractory carbides and nitrides, William Andrew, (1996)

[8] H. Okamoto, C-Zr (Carbon-Zirconium), J. Phase Equilib. 17 (1996) 162

[9] W. S. Williams, Scattering of electrons by vacancies in nonstoichiometric crystals of titanium carbide, Phys. Rev. 135 (1964) A505-A510

[10] E. Lewin, Design of carbide-based nanocomposite coatings, PhD Thesis, Acta Universitatis Upsaliensis, (2009)

[11] E. Lewin, E. Olsson, B. André, T. Joelsson, Å Öberg, U. Wiklund, H. Ljungcrantz, U. Jansson, Industrialisation study of nanocomposite nc-TiC/a-C coatings for electrical contact applications, Plasma Processes Polym. 6 (2009) 928-934

[12] E. Lewin, O. Wilhelmsson, U. Jansson, Nanocomposite nc-TiC/a-C thin films for electrical contact applications, J. Appl. Phys. 100 (2006) 054303

[13] D. Munteanu, C. Ionescu, C. Olteanu, A. Munteanu, F. Davin, L. Cunha, C. Moura, F. Vaz, Influence of composition and structural properties in the tribological behaviour of magnetron sputtered Ti-Si-C nanostructured thin films, prepared at low temperature, Wear 268 (2010) 552-557

[14] W. Gulbinski, T. Suszko, A. Gilewicz, B. Warcholinski, Z. Kuklinski, Structure and high-temperature tribological behavior of Ti-Si-C nanocomposite thin films, Surf. Coat. Technol. 200 (2006) 4179-4184

[15] M. Naka, H. Sakai, M. Maeda, H. Mori, Formation and thermal stability of amorphous Ti-Si-C alloys, Mater. Sci. Eng., A 226-228 (1997) 774-778

[16] T. Zehnder, J. Matthey, P. Schwaller, A. Klein, P. A. Steinmann, J. Patscheider, Wear protective coatings consisting of $\mathrm{TiC}-\mathrm{SiC}-\mathrm{a}-\mathrm{C}$ : $\mathrm{H}$ deposited by magnetron sputtering, Surf. Coat. Technol. 163-164 (2003) 238-244

[17] I. Bertóti, A. Tóth, M. Mohai, J. Szépvölgyi, Chemical structure and mechanical properties of Si-containing a-C:H and a-C thin films and their $\mathrm{Cr}$ - and $\mathrm{W}$-containing derivatives, Surf. Coat. Technol. 206 (2011) 630-639

[18] J. E. Krzanowski, J. Wormwood, Microstructure and mechanical properties of Mo$\mathrm{Si}-\mathrm{C}$ and $\mathrm{Zr}$-Si-C thin films: Compositional routes for film densification and hardness enhancement, Surf. Coat. Technol. 201 (2006) 2942-2952

[19] P. Eklund, J. Emmerlich, H. Högberg, O. Wilhelmsson, P. Isberg, J. Birch, P. O. Å Persson, U. Jansson, L. Hultman, Structural, electrical, and mechanical properties of nc-TiC/a-SiC nanocomposite thin films, J. Vac. Sci. Technol., B 23 (2005) 2486-2495 
[20] A. Schüler, P. Oelhafen, Photoelectron spectroscopic characterization of titaniumcontaining amorphous hydrogenated silicon-carbon films (a-Si $\left.\mathbf{1}_{\mathbf{1} \mathrm{x}} \mathbf{C}_{\mathbf{x}}: \mathbf{H} / \mathbf{T i}\right)$, Appl. Phys. A 73 (2001) 237-245

[21] T. Nakamori, T. Tsuruoka, T. Kanamori, S. Shibata, Effect of film thickness on TaSi-C high resistivity thin films for thermal printing heads, Trans. Inst. Electron., Inf. Commun. Eng., Sect. E (1987) 1133-1139

[22] P. Eklund, M. Beckers, U. Jansson, H. Högberg, L. Hultman, The $\mathbf{M}_{\mathbf{n}+\mathbf{1}} \mathbf{A} \mathbf{X}_{\mathbf{n}}$ phases: Materials science and thin-film processing, Thin Solid Films 518 (2010) 1851-1878 [23] M. W. Barsoum, $\mathbf{M}_{\mathbf{N}+1} \mathbf{A X} \mathbf{X}_{\mathbf{N}}$ phases: a new class of solids; thermodynamically stable nanolaminates, Prog. Solid State Chem. 28 (2000) 201-281

[24] M. W. Barsoum, T. El-Raghy, Synthesis and characterization of a remarkable ceramic: $\mathbf{T i}_{3} \mathbf{S i C}_{2}$, J. Am. Ceram. Soc. 79 (1996) 1953-1956

[25] J. Emmerlich, H. Högberg, S. Sasvári, P. O. Å Persson, L. Hultman, J. -. Palmquist, U. Jansson, J. M. Molina-Aldareguia, Z. Czigány, Growth of $\mathbf{T i}_{3} \mathbf{S i C}_{2}$ thin films by elemental target magnetron sputtering, J. Appl. Phys. 96 (2004) 4817-4826

[26] J. Palmquist, U. Jansson, T. Seppänen, P. O. A. Persson, J. Birch, L. Hultman, P. Isberg, Magnetron sputtered epitaxial single-phase $\mathbf{T i}_{3} \mathbf{S i C}_{2}$ thin films, Appl. Phys. Lett. 81 (2002) 835-837

[27] M. Braunovic, Electrical contacts - fundamentals, applications and technology, CRC Press, (2006)

[28] W. Gulbiński, T. Suszko, A. Gilewicz, B. Warcholiński, Z. Kukliński, Structure and high-temperature tribological behavior of Ti-Si-C nanocomposite thin films, Surf. Coat. Technol. 200 (2006) 4179-4184

[29] P. Eklund, Novel ceramic Ti-Si-C nanocomposite coatings for electrical contact applications, Surf. Eng. 23 (2007) 406-411

[30] R. J. Kerans, K. S. Mazdiyasni, R. Ruh, H. A. Lipsitt, Solubility of metals in substoichiometric $\mathrm{TiC}_{1-x}$, J. Am. Ceram. Soc. 67 (1984) 34-38

[31] J. Lauridsen, P. Eklund, T. Joelsson, H. Ljungcrantz, Å Öberg, E. Lewin, U. Jansson, M. Beckers, H. Högberg, L. Hultman, High-rate deposition of amorphous and nanocomposite Ti-Si-C multifunctional coatings, Surf. Coat. Technol. 205 (2010) 299305

[32] C. Lopes, N. M. G. Parreira, S. Carvalho, A. Cavaleiro, J. P. Rivière, E. Le Bourhis, F. Vaz, Magnetron sputtered Ti-Si-C thin films prepared at low temperatures, Surf. Coat. Technol. 201 (2007) 7180-7186

[33] M. W. Barsoum, T. El-Raghy, L. Farber, M. Amer, R. Christini, A. Adams, The topotactic transformation of $\mathrm{Ti}_{3} \mathrm{SiC}_{2}$ into a partially ordered cubic $\mathrm{Ti}\left(\mathrm{C}_{0.67} \mathbf{S i}_{0.06}\right)$ phase by the diffusion of Si into molten cryolite, J. Electrochem. Soc. 146 (1999) 3919-3923

[34] L. Cunha, F. Vaz, C. Moura, D. Munteanu, C. Lonescu, J. P. Rivière, E. Le Bourhis, Ti-Si-C thin films produced by magnetron sputtering: Correlation between physical properties, mechanical properties and tribological behavior, J. Nanosci. Nanotechnol. 10 (2010) 2926-2932

[35] M. Witthaut, R. Weiß, E. Zimmermann, A. Von Richthofen, D. Neuschütz, The formation of interface phases in the diffusion couple Ti-SiC, Z. Metallkd. 89 (1998) 623-628

[36] R. Yu, L. L. He, H. Q. Ye, Effects of Si and Al on twin boundary energy of TiC, Acta Mater. 51 (2003) 2477-2484

[37] Z. Zhang, Y. Luo, C. Xu, Phase and morphology evolution of TiC in the Ti-Si-C system, Int. J. Refract. Met. Hard Mater. 34 (2012) 32-35

[38] M. Andersson, S. Urbonaite, E. Lewin, U. Jansson, Magnetron sputtering of Zr-Si-C thin films, Thin Solid Films 520 (2012) 6375-6381

[39] K. Kádas, M. Andersson, E. Holmström, H. Wende, O. Karis, S. Urbonaite, S. M. Butorin, S. Nikitenko, K. O. Kvashnina, U. Jansson, O. Eriksson, Structural properties of amorphous metal carbides: Theory and experiment, Acta Mater. 60 (2012) 4720-4728 
[40] A. Leyland, A. Matthews, On the significance of the H/E ratio in wear control: A nanocomposite coating approach to optimised tribological behaviour, Wear 246 (2000) 1-11

[41] J. Lauridsen, P. Eklund, J. Jensen, A. Furlan, A. Flink, A. M. Andersson, U. Jansson, L. Hultman, Effects of A-elements $(\mathrm{A}=\mathrm{Si}$, Ge or $\mathrm{Sn})$ on the structure and electrical contact properties of Ti-A-C-Ag nanocomposites, Thin Solid Films 520 (2012) 51285136

[42] O. Wilhelmsson, P. Eklund, H. Högberg, L. Hultman, U. Jansson, Structural, electrical and mechanical characterization of magnetron-sputtered V-Ge-C thin films, Acta Mater. 56 (2008) 2563-2569

[43] J. Emmerlich, P. Eklund, D. Rittrich, H. Högberg, L. Hultman, Electrical resistivity of $\mathbf{T i}_{\mathbf{n}+\mathbf{1}} \mathbf{A C}_{\mathbf{n}}(\mathbf{A}=\mathbf{S i}, \mathbf{G e}, \mathbf{S n}, \mathbf{n}=\mathbf{1 - 3})$ thin films, J. Mater. Res. 22 (2007) 2279-2287

[44] K. E. Spear, D. F. Palino, Phase equilibria in the Nb-Ge-C system, Mater. Res. Bull. 18 (1983) 549-558

[45] P. Eklund, M. Dahlqvist, O. Tengstrand, L. Hultman, J. Lu, N. Nedfors, U. Jansson, J. Rosén, Discovery of the ternary nanolaminated compound $\mathrm{Nb}_{2} \mathbf{G e C}$ by a systematic theoretical-experimental approach, Phys. Rev. Lett. 109 (2012), 035502 


\section{Deposition processes}

There are several techniques for the deposition of thin films. Wet chemical processes such as electroplating use an electrolyte to transport metal ions and deposits them on a conducting surface. In vapor deposition the material is transported to the substrate in a gas phase. Vapor deposition can be further divided into the categories of chemical vapor deposition (CVD) and physical vapor deposition (PVD). In CVD the film growth occurs through chemical reactions introduced by the precursors in gas phase. This method is useful for complex substrate surfaces since the gas can go into cavities. However, the reactions in CVD often require high temperatures, which limit the choices of substrates. For heat-sensitive substrates PVD can instead be used. One common way of vaporizing the material in PVD is by sputtering where atoms in the source material are hit by ions and ejected towards the substrate [1]. The use of sputtering was reported by Grove as early as 1852 [2]. Sputtering, or more precisely a variant called dc magnetron sputtering, is also the technique used for all the films analyzed in thesis. Therefore, magnetron sputtering will be described more in detail in the following section.

\subsection{Magnetron sputtering}

Fig. 4.1 shows a schematic figure of the magnetron sputtering process. In the process atoms are ejected from the source (target) by ions from the plasma. The atoms then travel through the chamber (and the plasma) and some of them end up at the substrate where they can be deposited. To avoid contamination from other elements in the film, magnetron sputtering is performed at low background pressure in a vacuum chamber. A gas is introduced to the chamber to provide the ions that ejects the target-atoms. If no reactions with the gas are wanted (non-reactive sputtering) an inert gas, typically $\mathrm{Ar}$ (as for the films in this thesis), is used. Otherwise e.g. oxides and nitrides can be deposited by the use of $\mathrm{O}_{2}$ and $\mathrm{N}_{2}$ as gas, respectively. The ions are formed in a plasma ${ }^{\dagger}$, which is ignited when free electrons (available in the chamber due to, e.g., cosmic radiation or thermal energy) are accelerated by an applied electric field and undergoes inelastic collisions with neutral gas atoms.

\footnotetext{
$\dagger$ Although I here mainly talk about the plasma ions, the plasma in itself is a quasi-neutral gas. This means that it consists of electrons, ions, and neutrals without any net-charge. [3]
} 
At the target, a negative potential is used to attract and accelerate the ions in the plasma. When the ion hits the target several events can occur. Some of them are illustrated in the left part of Fig 4.1. Firstly, secondary electrons and photons can be emitted. The secondary electrons are important because they ionize atoms in the plasma and in this way the plasma can be sustained. The ions, in turn can knock out (sputter) atoms from the target, either directly or via a cascade of collisions. How many atoms that are sputtered per incident ion is called sputter yield and is dependent on the sputtered material and the energy of the impinging ions.

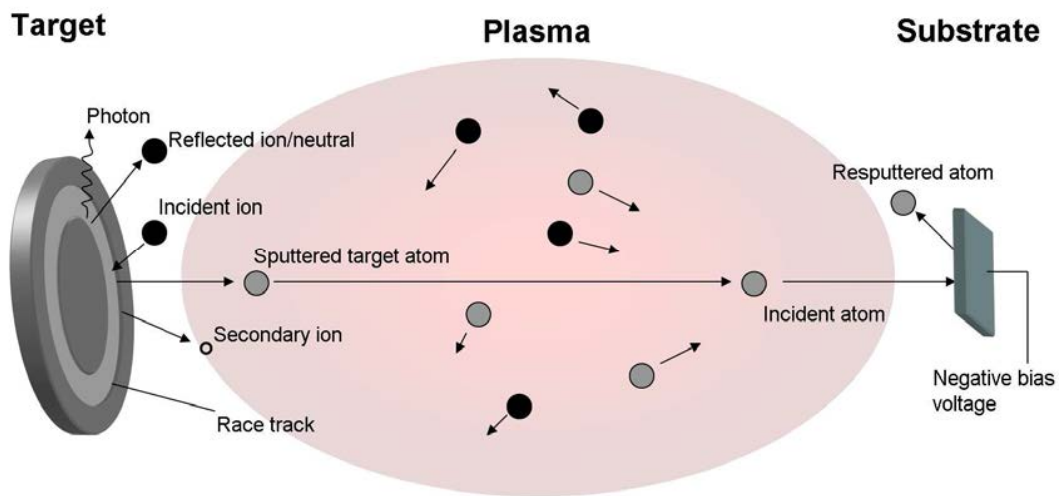

Fig. 4.1 Schematic figure of the sputtering process. Atoms from the target are transported through the plasma and deposited on the substrate.

In order to increase the degree of ionization close to the target, where the ions are needed for the sputtering process, magnets are put behind the target (hence the name magnetron sputtering). The formed magnetic field will trap the secondary electrons and thus confine the space where most of the ions are created. The confinement of the electrons will cause an uneven sputter rate over the surface of the target where most of the sputtered atoms come from the so called race track. However, too much confinement of the plasma near the target can be undesirable since plasma ions also modify the growth conditions at the substrate. This problem can be solved by an unbalanced magnetron, in which the magnetic field is strengthened at the inner or outer parts of the target. Thereby more of the secondary electrons can escape from their confinement and ionize atoms further away from the target.

The sputtered atoms will travel in the direction they are ejected until they reach the chamber wall, the substrate or collide with another atom (or ion). In such collisions, the atoms will change direction. If collisions occurs often enough the motion of the atoms will become random. These atoms are called thermalized. The average distance an atom can travel before a collision is called the mean free path, $\lambda$ [4]. At an Ar pressure of 0.4-0.5 Pa, which is used as working pressure for the sputter depositions in this thesis, $\lambda$ is roughly a couple of centimeters with longer mean free paths for the lighter elements. 
An atom that lands on the substrate surface it is called adatom. The sticking coefficient is the probability that the atom will stay on the surface. If the adatom has some energy it can move around on the surface. The adatom mobility can be manipulated with bombardment of energetic particles. This can be achieved by applying a negative bias voltage, which attracts the ions in the plasma. The ion bombardment can increase the nucleation rate and the film density, but also the stress state in the film [5]. If too high bias is applied to the substrate, the plasma ions will start to resputter the material of the substrate.

With magnetron sputtering it is possible to deposit a wide range of materials from metals to insulators. For deposition of thin films consisting of more than one element, composite targets are available and these are often used in industrial processes where the wanted composition is known. However, when investigating how different compositions cause structural changes like in Paper 1-3 and 6, the use of several elemental targets will give a larger possibility to control the composition. Elemental targets were therefore used for the deposition of all films in this thesis.

The text above describes how the sputtering is caused by ions accelerated by a negative potential. There are several different techniques to do this. For the films in this thesis, a constant voltage was applied ( $d c$ magnetron sputtering). This technique can not be used for target materials with a resistivity larger than $10^{6} \Omega \mathrm{cm}[1]$. For these material, an ac or radio frequency (rf) voltage need to be applied (ac or rf magnetron sputtering). The high frequency will lower the impedance of the material and allow a current to pass. Since the electrons follow the changes in the electric field much faster than the ions, the target will become self-biased to a negative potential. In this way the sputtering process can go on in the same way as for a dc target with positive ions that sputter away target atoms. Pulsed magnetron sputtering can be used if arcing is a problem in the system. By inversing the voltage in a pulse the electrons in the plasma can discharge the target to prevent large charges from building up.

\section{References}

[1] M. Ohring, Materials science of thin films, $\mathbf{2}^{\text {nd }}$ ed., Academic press, (2002)

[2] P. M. Martin, Handbook of deposition technologies for films and coatings: science, applications and technology, $3^{\text {rd }}$ ed., Elsevier Science, (2010)

[3] F.F. Chen, Introduction to plasma physics and controlled fusion-Volume 1: Plasma physics, $2^{\text {nd }}$ ed., Plenum Press, (1984)

[4] J.F. O'Hanlon, A user's guide to vacuum technology, $3^{\text {rd }}$ ed., John Wiley \& Sons, (2003)

[5] I. Petrov, L. Hultman, J.E. Greene, Microstructural evolution during film growth, J. Vac. Sci. Technol., A 21 (2003) 117-128 


\section{Characterization}

A large number of techniques are needed to analyze the microstructure and properties of thin films. In this chapter some of the techniques used in this thesis are described. The first is transmission electron microscopy, integrated with energy-dispersive $X$-ray spectroscopy (EDX). TEM/EDX is used in Paper 1-6 to observe the structure and elemental distribution of the materials. Also scanning electron microscopy (SEM), which is another electron microscopy technique used in (Paper 1 and 6) is briefly described. Next, different methods using $X$-ray diffraction are discussed. These methods include $\theta-2 \theta$ (Paper 2 and 6) and gracing incidence (Paper $\mathbf{1}$ and 3) X-ray diffraction, which are used for identifying the crystalline phases and texture of the materials. They also include pole figures and the $\sin ^{2} \psi$-method (Paper 2), which are used to determine the epitaxy and measure stress, respectively. With a low angle of incidence the X-rays will be reflected rather than diffracted. $X$-ray reflectivity can be used to determine the density of a material (Paper 6). X-ray photoelectron spectroscopy (XPS) is used to determine the composition (Paper 1-6) and describe the bonds between the atoms (Paper 1-3 and 6) is described. Finally methods for characterization of the electrical properties resistivity (Paper 1, 3, and 6) and contact resistance (Paper 1 and 6) are described.

\subsection{Transmission electron microscopy (TEM)}

One of the more important techniques considering the work in this thesis is transmission electron microscopy. It is a powerful technique since it combines high spatial resolution with crystal information from electron diffraction. In Papers 1-3 and 6 it is used to help determine the structural evolution of the studied materials on the nano-scale. TEM can also be combined with other analytic methods to get information about the distribution and composition of the elements in the film. One example is EDX, which is used in Paper 2 in order to show segregation of $\mathrm{Si}$. In the TEM, electrons are emitted from an electron gun and accelerated by a high voltage. For the material science of transition metal carbide based materials, the acceleration voltage typically lies between $\sim 100-300$ $\mathrm{kV}$. An advanced set-up of magnetic lenses is then used to focus and direct the beam through the microscope and form an image of the sample. This section will describe how an image or diffraction pattern is formed and used after a beam with parallel electrons has interacted with the sample, followed by descriptions of EDX and sample preparation. A discussion about electron-beam-induced crystallization during high resolution TEM studies (Paper $\mathbf{4}$ and 5) is presented in Ch. 6. 


\subsubsection{Imaging}

Since the wavelength of the electrons at $200 \mathrm{keV}$ is very short $(2.5 \mathrm{pm})$, the theoretical resolution of the microscope is as high as $0.02 \AA$. In practice, due to instrumental and atomic aberrations, the best spatial resolution is not that high, but is still enough for atomic resolution.

Fig. 5.1 shows a simplified model of the electron path through the sample and down to a fluorescent screen or CCD-camera. Fig. 5.1a) shows the imaging system, which consists of three lenses. The objective lens forms the first image of the sample. The corrections of this lens are important since all imaging errors made by the lens will be magnified by the other lenses in the system. The second lens is called the intermediate lens. By changing the lens current for the intermediate lens the operator can switch between diffraction and imaging simply by pressing a button. The last lens, the projector lens, magnifies the image or diffraction pattern of the sample even further.

a)

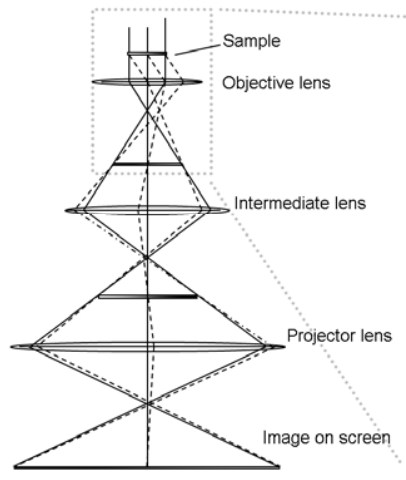

b)

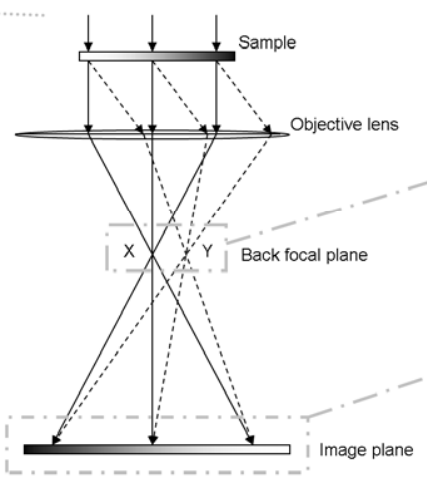

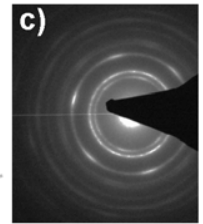

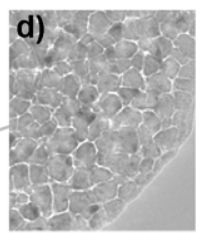

Fig. 5.1 a) simplified model of the electron path through the imaging lenses, b) projection of the image in the objective lens, c) selected area electron diffraction, and d) real space micrograph.

Fig. 5.1b) shows the projection in the objective lens. As the electrons goes through the sample they can interact with material in several different ways. Some of them are transmitted without any change (solid lines), while others are scattered by the atoms in the sample (dashed lines). All the electrons scattered in one direction will come together in a point in the back focal plane, i.e., point $\mathrm{X}$ for the direct beam and point $Y$ for the scattered electrons in the figure. All the points together make up the electron diffraction pattern. The electron path can thereafter be further extended to the image plane where an image of the sample is formed.

An example of an electron diffraction pattern (Ti-Si-C sample, Paper 2) is shown in Fig. 5.1c). The image of the diffraction pattern is formed by placing the object plane of the intermediate lens in the back focal plane of the objective lens. The pattern in the figure consists of circles which are more intense in some of the areas. 
The black triangular shape is a beam blocker, which is used to protect the CCDcamera from the high intensity of the directly transmitted beam. From the pattern we can obtain information about the lattice spacings (radii of the circles), crystal structure (distribution of the circles), and crystal orientation. A circle with homogenous intensity indicates a polycrystalline structure with randomly oriented crystallites. In the viewed sample there is, however, some ordering (a (111) preferred direction) among the crystallites and therefore the third circle from the center has higher intensity in some directions (the $\{220\}$ spots). In this way more and more order will finally give rise to a dot pattern when the intensities from the rings are concentrated in specific directions or vanish depending on the orientation of the grains. Amorphous material (studied in Paper 3-5) will scatter equally in all direction and therefore only form very diffuse circles. There is often a wish to have diffraction patterns from only one part of the prepared sample (e.g., excluding the substrate). This can be done by inserting an aperture (selected area aperture) in the image plane of the objective lens. The area of the image where the beam then can pass is the same as from which the viewed diffraction pattern originates.

The real space image corresponding to Fig. 5.1c) is shown in Fig. 5.1d). The image is formed by placing the object plane of the intermediate lens in the image plane of the objective lens. The scattered electrons are important for imaging since they are the origin of most of the image contrast. The image contrast can be increased by inserting an aperture (objective area aperture) in the back focal plane of the objective lens. If the electrons in point Y (Fig. 5.1b)) are blocked, regions scattering more in this direction will appear darker since these electrons do not contribute to the image anymore. If the transmitted beam (point $\mathrm{X}$ ) is screened by the objective aperture, all the image contrast is made up of scattered electrons. All regions not scattering electrons (e.g., a hole in the sample) will appear totally black and this technique is therefore called dark field imaging. The technique can be useful for identifying crystal grains with a certain orientation, by selecting this orientation with the objective area aperture in the diffraction mode. These grains will then appear bright in imaging.

Thus, atomic resolution together with the ability to easily record diffraction patterns is one of the big advantages of TEM since it is possible to obtain both real and reciprocal space information from a specifically selected part of the sample. The microscope can also be equipped with other instruments such as EDX (see Section 5.1.2) or EELS to be able to obtain compositional information.

There are also some drawbacks with TEM. One disadvantage is that the sample has to be electron transparent (i.e. $<100 \mathrm{~nm}$ for most materials). This means an extensive sample preparation (See Section. 5.1.3), which in worst case might affect the composition. The sample preparation usually gives only a very small volume from each sample that can be imaged. The investigated volume then has to be assumed representative for the whole film. Care should also be taken not to misinterpret features, e.g., overlapping grains when the three-dimensional volume of the sample is projected into a two-dimensional image. 


\subsubsection{Energy-dispersive X-ray Spectroscopy (EDX)}

As mentioned earlier, TEM can be implemented together with other instruments. In EDX (also called EDS), the energy of emitted X-rays from the sample is analyzed. This is possible because atomic electrons in the sample can be excited by the beam. After one excitation, an electron from a shell further out will take the place of the excited electron in order to lower the total energy of the atom and at the same time an X-ray photon is emitted. The energies of the emitted photons are characteristic for each element and can therefore be used to identify the elements [1]. As an example, the EDX spectrum from a Ti-Si-C sample is shown in Fig. 5.2. In the spectrum the peaks of the elements in the film is seen. ${ }^{\dagger}$ The intensity of the different peaks depends on composition, but also on the type element, the thickness of the sample and the crystallographic orientation of crystallites in the sample. Sensitivity factors can be used in quantitative analysis, but care should be taken especially for the lighter elements (in this case $\mathrm{C}$ ), which are difficult to quantify.
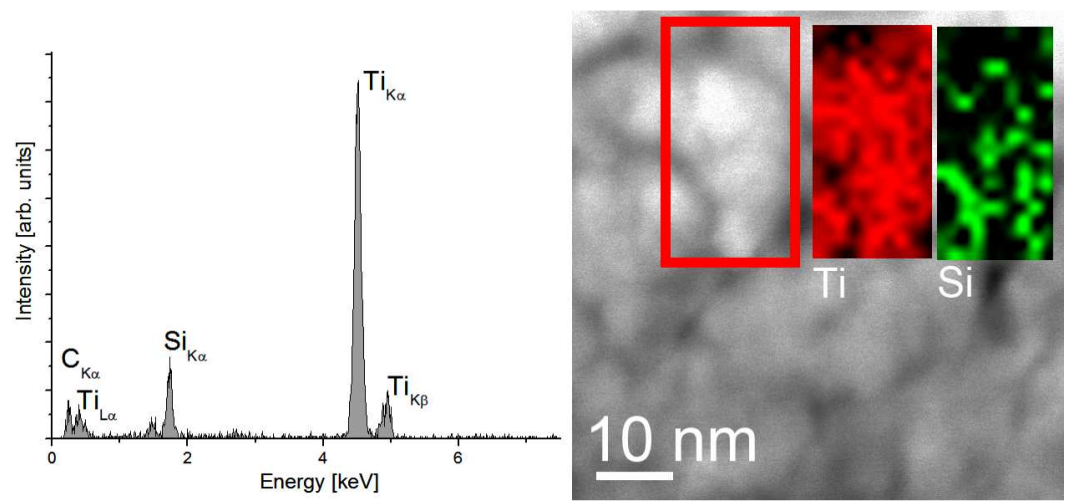

Fig. 5.2 a) example of EDX spectrum from a Ti-Si-C sample. b) STEM micrograph from the same Ti-Si-C sample with EDX map of Ti and Si from the marked region inserted.

A special variant of TEM often used in connection with EDX is scanning transmission electron microscopy (STEM). In STEM the beam is focused to a small spot and the image is formed by continuous scanning over an area. The advantage of this is that an EDX spectrum can be acquired from a very small region. The use is shown in Fig. 5.2b), where elemental mapping of $\mathrm{Si}$ and $\mathrm{Ti}$ (insets) have been performed. The maps are created by acquiring one EDX spectrum for each point in the marked region. In each spectrum the intensity of the $\mathrm{Ti}_{\mathrm{K} \alpha}$ and $\mathrm{Si}_{\mathrm{K} \alpha}$ peak is integrated and plotted in the $\mathrm{Ti}$ and $\mathrm{Si}$ map, respectively. This example comes from Paper 2, and shows how Si has segregated from the TiC structure out to the grain boundaries.

\footnotetext{
${ }^{\dagger}$ In addition also a small $\mathrm{Al}$ peak just below the $\mathrm{Si}$ peak can be seen. This peak probably originates from material coming from the $\mathrm{Al}_{2} \mathrm{O}_{3}$ substrate.
} 


\subsubsection{Sample preparation}

Depending on the cutting different information can be obtained as illustrated in Fig. 5.3. The sample in the figure has a columnar structure, which is seen for several samples in this thesis. If a cross-sectional specimen (cut A) is prepared the growth evolution can be studied. This is useful for example for showing how the thickness of the initial epitaxial layer changes with Si content in Paper 2. However since the columns have small diameters they will overlap and elemental mapping of the phase between the columns is hard to achieve. In Paper 2 this problem is solved by instead using a plan-view sample (cut B in Fig 5.3). The columns are now viewed along their elongated axis so that the projected image will have a minimum of overlapping columns. Thereby, the segregation of $\mathrm{Si}$ out of the columns could be mapped by EDX.
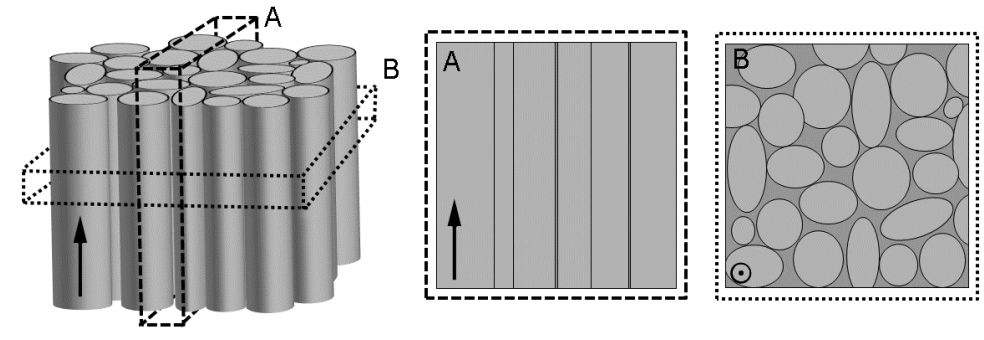

Fig. 5.3 Schematic of a columnar structure with A and B marking the ways of cutting the sample into a cross-section and a plan-view, respectively. Growth direction is marked in the figures.

Independent of the choice of cutting the sample needs to be thin enough to be able to transmit electrons through the material. For most material, this means a specimen thickness of less than $100 \mathrm{~nm}$.

There are several ways to prepare electron-transparent specimens. Most of the TEM images presented in this thesis are from cross-sectional specimens where the film was cut and glued into a grid with two film sides facing each other. The specimens were then mechanically polished down to a thickness of $\sim 50 \mu \mathrm{m}$ and a surface roughness of $\sim 1 \mu \mathrm{m}$ before they were put in an ion miller. In the ion miller the specimens were thinned further by $\mathrm{Ar}^{+}$ions with energy of $5 \mathrm{keV}$ to achieve electron transparency. In a final step the energy of the $\mathrm{Ar}^{+}$ions is reduced to $2 \mathrm{keV}$ for $10 \mathrm{~min}$ in order to remove sputter-induced residuals from the surface.

Also plan-view specimens are used. These are prepared from a circular disk of the sample, which is cut and polished from the substrate side. In order to avoid the supporting substrate from cracking during the process, only the center of the disk is thinned to a thickness of $\sim 50 \mu \mathrm{m}$, with the help of dimpling, while the rest of the specimen is left with a thickness $\sim 100 \mu \mathrm{m}$. The specimen is then ion-milled to electron transparency in the center. If the specimen is ion-milled only from the substrate side, voided regions between the columns can be observed. Therefore, 
the specimen is also ion-milled from the top. One difficulty with this is to know how far up in the film the specimen is viewed and several iterations going between the ion-miller and TEM can be necessary.

An important aspect is how the sample preparation affects the structure and chemical composition of the material. It is, for example, shown that the cleansputtering with $\mathrm{Ar}^{+}$ions prior XPS measurements changes the binding structure of metastable $\mathrm{Ti}-\mathrm{Me}-\mathrm{C}(\mathrm{Me}=\mathrm{Al}, \mathrm{Fe}, \mathrm{Cu}$ or $\mathrm{Pt})$ already at low ion energies $(<4 \mathrm{keV})$ [2]. This is in the same range as the $\mathrm{Ar}^{+}$energy used for the ion milling in TEM sample preparation and the question of ion induced damage in the samples are thus motivated. In Paper 4 I therefore compare $\mathrm{Nb}-\mathrm{Si}$-C TEM specimens prepared by ion milling, and specimens prepared by the small angle cleavage technique (SACT) [3]. In SACT, the sample is cleaved in such way that cross sectional electron transparent regions are formed. Therefore, no ion milling is necessary for this method. However, often only a very small region will be electron transparent [4]. In the case of $\mathrm{Nb}-\mathrm{Si}-\mathrm{C}$ only modest differences were seen between the two methods and the conclusion was that the ion milling did not have any distinguishable effect on these samples.

\subsection{Scanning electron microscope (SEM)}

Like TEM, SEM detects electrons to form an image. The acceleration voltage is, however, much lower (typically 5-30 keV). This gives a lower resolution than TEM (although still much higher than an optical microscope), but is much easier to use since it needs little or no sample preparation if the sample is conductive, vacuum compatible and unaffected by the electron beam.

SEM uses a scanning electron beam that is moving over the surface of the sample. The primary electrons from the beam interact with the material and the electrons emerging out from the sample is detected in order to form an image of the sample. Detection of secondary electrons emitted from the outer electron shells will give a topographical contrast in the image. Since these electrons have low energy $(<50 \mathrm{eV})$ they will come from a confined place close to the surface. There are also electrons that are elastically backscattered by the atom nuclei. Heavier atoms will backscatter more and therefore a compositional contrast can be imaged. However, this will not give information of which elements there are in the film. For identification and quantification of elements SEM is often combined with an EDX detector.

\section{$5.3 \quad X$-ray diffraction (XRD)}

$\mathrm{XRD}$ is extensively used in material science since it is both easy to use and nondestructive. In XRD, X-rays are radiated onto a material. The X-rays will interact with the material and information about the crystal structure can be obtained from the diffracted X-rays. 


\subsubsection{Bragg's law}

The reason to use $\mathrm{X}$-rays is that their small wavelength, $\lambda,\left(1.54 \AA\right.$ for $\left.\mathrm{Cu}_{\mathrm{K} \alpha}\right)$ is comparable to the distance between the atoms in materials, i.e., $\mathrm{X}$-rays can resolve the atomic plane spacing. The X-rays diffract with constructive interference according to Bragg's law

$n \lambda=2 d_{h k l} \sin (\theta)$,

where $n$ is an integer, $d_{h k l}$ the plane distance between two planes with index $h k l$, and $\theta$ the scattering angle. Not all combinations of $h k l$ will give a diffraction peak. The allowed reflections are given by the structure factor, which can be calculated from the crystal structure. [5] The peak positions are dependent on which atoms are present in the structure. Thereby each material will have its own "fingerprint" from which it can be identified using XRD.

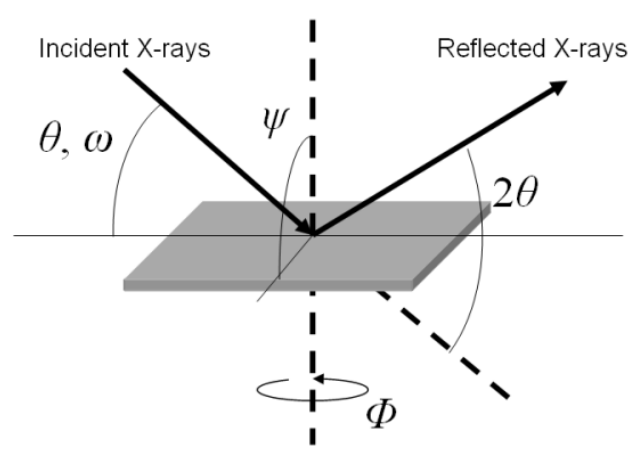

Fig. 5.4 Notation of angles used in XRD.

The X-ray peaks can only be detected if the condition in Eq. 5.1 is fulfilled, which implies that the material is crystalline with large enough grains. If the grain size is reduced this is observed as a drop in peak intensity and a peak broadening can also be seen when. The peak broadening can be used to calculate the grain size by using, the Scherrer's formula [6]. (Paper 1, 3, and 6). When the grain size becomes smaller than $2-5 \mathrm{~nm}$ it is no longer possible to see any reflections. The material is then called $\mathrm{X}$-ray amorphous.

\subsubsection{Different X-ray diffraction methods used}

In order to find the planes that fulfill Bragg's law and in which direction they are oriented, both the incident X-rays and detector as well as the sample orientation need to be varied. The notations of the varied angles in this thesis are illustrated in

Several different methods to vary these angles in order to find constructive interference are available. The three of them used in this thesis are illustrated in Fig. 5.5. These are a) $\theta-2 \theta$, b) gracing incidence $X$-ray diffraction (GIXRD), and c) 
pole figures. In the figures an epitaxial (A) and a poly-crystalline (B) film of TiSi-C (Paper 2) are shown.

a)

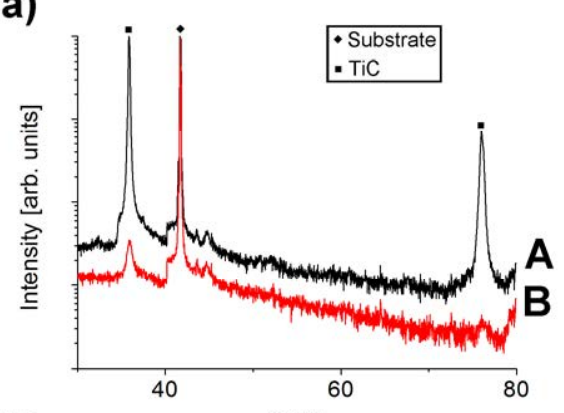

b)

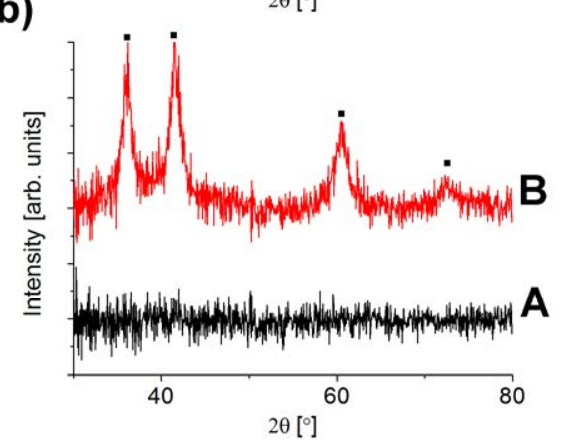

c)
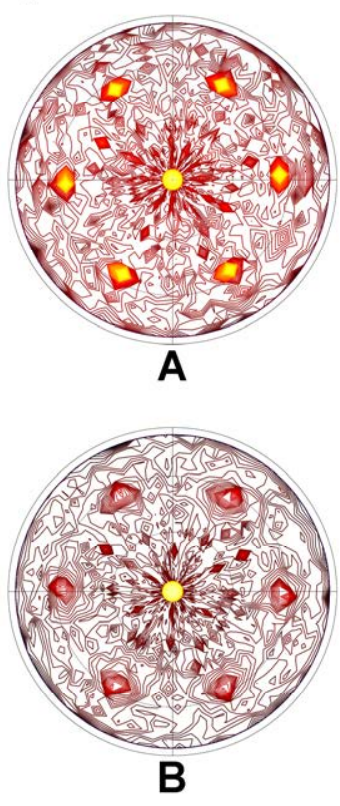

Fig. 5.5 Epitaxial $\mathrm{Ti}_{x}(\mathrm{~A})$ and polycrystalline $T i-S i-C(B)$, viewed with different $X$-ray techniques. a) $\theta-2 \theta, b)$ GIXRD, and c) pole figure of TiC 200.

In a $\theta-2 \theta$ measurement (illustrated by Fig. 5.5a)) the angle of incident and reflected beams are changed simultaneously and always kept equal to each other. This means that only crystal planes parallel to the surface will contribute to the diffraction pattern. Film A, which has all the (111) planes oriented this way, therefore shows much stronger peaks than $\mathrm{B}$ in which the planes are more randomly oriented and the crystallites are smaller.

GIXRD (Fig. 5.5b)) instead uses an incident beam at a small constant angle, $\omega$, and varies the outgoing angle, $2 \theta$. This means that the planes fulfilling Bragg's diffraction condition in general are not parallel to the surface. GIXRD is therefore useful when having non-textured materials with grains randomly oriented like film B. For the substrate and film A, the Bragg condition is never fulfilled and therefore no peaks can be seen.

In a pole figure (Fig. 5.5c)) the outgoing beam and the detector are fixed at one chosen $\theta-2 \theta$ value, i.e., at one specific plane distance. The sample is then rotated in the $\psi$ and $\Phi$ directions and the detected intensity can be plotted onto a 
stereographic projection. If the sample is highly textured, as for A, the Bragg condition will only be fulfilled in certain directions and peaks will be seen in the pole figure. If we instead have a sample with grains more randomly distributed in the film the pole intensity will decrease, as for B. In Fig. 5.5c) the $\theta-2 \theta$ value was set to correspond to $d_{200}$ for TiC. This value coincides with the $d_{0006}$ value of the $\mathrm{Al}_{2} \mathrm{O}_{3}(0001)$ substrate peak and therefore an intense peak can be seen at the center of both pole figures.

\subsubsection{Strain measurements ( $\sin ^{2} \Psi$-method)}

In Paper 2 a shift of the 111-peak was seen with increasing Si content. In order to exclude the possibility that this shift was due to strain the $\sin ^{2} \psi$-method was used. The accuracy of this method should not be overestimated, but the technique gives an estimate of the in-plain stress, $\sigma$ and allows for calculation of the strain free lattice parameter $a_{0}$. [7]

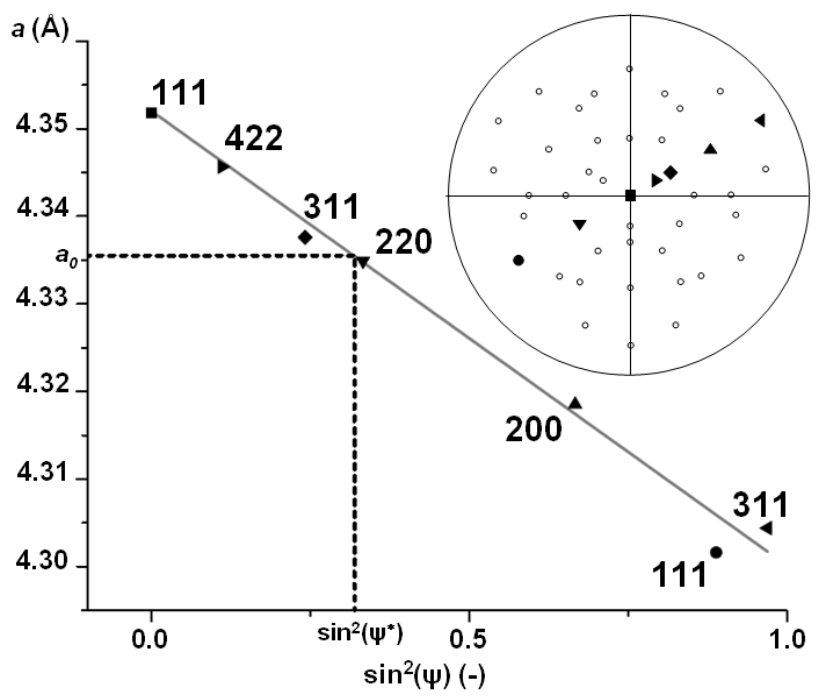

Fig. 5.6 Measurements of the lattice parameter $v s . \sin ^{2} \psi$, and stereographic projection with the measured crystal-directions (filled symbols).

A tensile stress in a thin film will cause an expansion of the lattice planes in the direction normal to the surface. At the same time a compression will be seen of the planes parallel to the surface. The expansion and compression is coupled by the Poisson ratio, $v$. In the $\sin ^{2} \psi$-method this change is often observed by measuring the plane distance for a certain plain, $d_{h k l}$, at different $\psi$. However, if the stress is measured on an epitaxial film (Paper 2) different $d_{h k l}$ must be chosen for different directions of $\psi$. In this case the lattice parameter $a$, rather than a selected plane spacing is used in the plot against $\sin ^{2} \psi$. 
One example of a stress measurement is shown in Fig. 5.6. The data points are marked with the indexes of the $d_{h k l}$ from which $a$ was calculated. The positions of the poles are marked with the symbols from plot, in the stereographic projection (inset Fig. 5.6). The open circles in the inset show other directions from which $a$ can be measured in the crystal. The figure shows that a linear curve (solid line) can be fitted to the data points. The curve has the equation

$a=m \sin ^{2} \psi+k$

where $m$ and $k$ are constants.

For a stress independent of the azimuth angle $\Phi$, the following equation can be derived (see [7] for a more detailed derivation).

$\varepsilon=\frac{1+v}{E} \sigma \sin ^{2} \psi-\frac{2 v}{E} \sigma$

Also knowing that the stress can be expressed as the relative change in $a$ from the strain free lattice parameter it is possible to combine Eq. 5.2 and 5.3.

$$
\frac{1+v}{E} \sigma \sin ^{2} \psi-\frac{2 v}{E} \sigma=\varepsilon=\frac{a-a_{0}}{a_{0}}=\frac{m}{a_{0}} \sin ^{2} \psi-\frac{k-a_{0}}{a_{0}}
$$

Identifying the term in front of the $\sin ^{2} \psi$ term gives the stress

$$
\frac{1+v}{E} \sigma=\frac{m}{a_{0}} \Leftrightarrow \sigma=\frac{m E}{(1+v) a_{0}} \text {. }
$$

If $a_{0}$ is not known this can be calculated from the Eq. 5.2 by first putting $\varepsilon=0$ in Eq. 5.3, which gives a value for the strain-free direction $\psi^{*}$.

$$
\varepsilon=0 \Rightarrow 0=\frac{1+v}{E} \sigma \sin ^{2} \psi^{*}-\frac{2 v}{E} \sigma \Leftrightarrow \sin ^{2} \psi^{*}=\frac{2 v}{1+v}
$$

The value for $\sin ^{2} \psi^{*}$ can then be used in Eq. 5.2 to calculate $a_{0}$. From the equations it is clear that the $\sin ^{2} \psi$-method assumes that the Poisson ratio for the material is known. In the example in Fig. 5.6, the value 0.19 [8] (TiC) is used which gives $\sin ^{2} \psi^{*}=0.32$. Both $\sin ^{2} \psi^{*}$ and the corresponding $a_{0}$ have been marked in the figure.

\subsubsection{X-ray reflectivity (XRR)}

If a $\theta-2 \theta$ measurement is carried out at very low angle $\left(2 \theta<4^{\circ}\right)$ it is instead referred to as X-ray reflectivity (XRR). Below a certain angle, called the critical angle, all the X-rays will be totally reflected by the film. At the critical angle the intensity drops dramatically as shown in Fig. 5.7a). The $2 \theta$-value for the critical angle depends on the refractive index of the film. Since the refractive index is a 
function of the electron density the density of the film can be calculated from the critical angle if the composition of the film is known. As an example film B in Fig. 5.7a) has a higher critical angle than film A and therefore, film A has a higher electron density. This was used in Paper 6, where the density calculated from XRR was compared with a theoretically calculated density. In this way it could be shown that the films were porous with a correlation between the porosity, the oxygen content and the resistivity of the films.
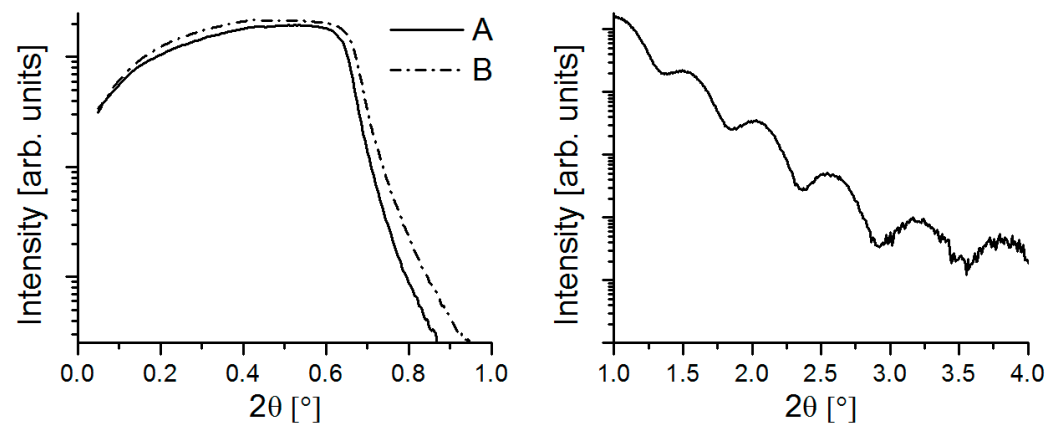

Fig. 5.7 XRR measurements for a) density b) thickness.

For thin films, typically less than $100 \mathrm{~nm}$ thick, constructive interference between the substrate surface and the film surface will at low angles give rise to so called Kiessig fringes as shown in Fig. 5.7b). The shape of the fringes and the distance between them depend on the film thickness and the surface roughness. These two properties can therefore be modeled from the data. In this work, the modeled thickness has been used for calculating the growth rates of the films.

\section{$5.4 X$-ray photoelectron spectroscopy (XPS)}

In XPS or ESCA (Electron Spectroscopy for Chemical Analysis) X-ray photons are used to eject electrons from the core levels of the analyzed material. Since both the photon energy $\left(E_{p}\right)$ and the work function $(W)$ are known the detected kinetic energy of the emitted electrons $\left(E_{k}\right)$ can be used to calculate the binding energy $\left(E_{b}\right)$.

$E_{b}=E_{p}-E_{k}-W$

The binding energy is characteristic for each material and by plotting $E_{b}$ against the intensity a qualitative analysis of the composition can be done. For a quantitative analysis the area of each peak must be calibrated using elemental specific sensitivity factors. The sensitivity factors can be obtained by XPS measurements on samples with known composition. In this thesis the composition of selected sets of samples were therefore also measured by Elastic Recoil Detection Analysis (ERDA) or Rutherford Backscattering Spectrometry (RBS) 
The orbital from which the electrons are emitted will be affected by neighboring atoms. This is seen as a small chemical shift of the peak and thereby different bonds in the material can be detected.

Even if the X-rays penetrate deep into the material, the escape depth of the photoelectrons is usually less than $10 \mathrm{~nm}$, which makes XPS a surface sensitive method. For analysis deeper down into the material, sputtering is often used to remove the top surface.

\subsection{Electrical resistivity}

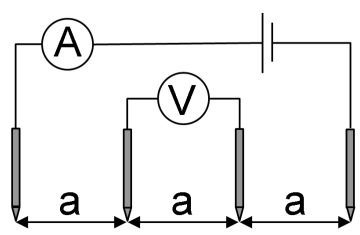

\section{Film}

Fig. 5.8 Schematic of a four point probe measurement setup

A four point probe instrument has been used to measure resistivity. To avoid substrate effects, the thin films for this purpose were deposited onto isolating substrate material $\left(\mathrm{SiO}_{2}\right)$. An illustration of the setup is shown in Fig. 5.8. During the measurement the four probes sitting in a line at equal distances are pressed against the material. A current is applied between the outer probes and the voltage between the two inner probes is measured. Since there is no current going through the inner probes there is no contact resistance influencing the measurement. In the case of thin films were the thickness of the film, $t_{f}$, is much smaller than the distance between the contacts, $a$, and an infinite surface the expansion of the current can be assumed to be cylindrical around the conducting probes. The crosssectional area, $A_{c}$, at a radial distance $r$ from a probe through which current flows is then given by

$A_{c}=2 \pi r t_{f}$

Since the voltage is measured between the inner probes an expression for the resistance, $R$, in the material is given by

$R=2 \int_{a}^{2 a} \frac{\rho d r}{2 \pi r t_{f}}=\frac{\rho \ln (2)}{\pi t_{f}}$

In Eq. 5.9, $\rho$ is the resistivity to be calculated. Rewriting Eq. 5.9 and applying Ohm's law gives

$\rho=\frac{\pi t_{f}}{\ln (2)} R=\frac{\pi t_{f}}{\ln (2)} \frac{U}{I} \approx 4.532 t_{f} \frac{U}{I}$. 
$U$ and $I$ are measured in the four-point probe setup, while the thickness of the film must be obtained with some other method. In this thesis this was done using crosssectional SEM. To correct for the finite sample size the obtained resistivity must be multiplied by a factor, which with a sample size of $(10 \times 10 \mathrm{~mm})$ and the probe used $(\mathrm{a}=0.5 \mathrm{~mm})$ is 0.9822 .

\subsection{Electrical contact resistance}

The contact resistance is an important property for all contacts. In an application the contact resistance should be both low and stable over time. There are different setups for measuring the contact resistance. In Paper $\mathbf{1}$ a crossed-cylinder geometry, as shown in Fig. 5.9a), was used. In this setup two Ni-plated $\mathrm{Cu}$ cylinders (20 mm length, $10 \mathrm{~mm}$ diameter) is used. One cylinder is coated with $\mathrm{Ag}$ the other with the contact material of interest. At the same time as a force is applied a current is sent through the cylinders as shown in the figure. By measuring the voltage and the current, the contact resistance can be calculated by Ohm's law.

a)

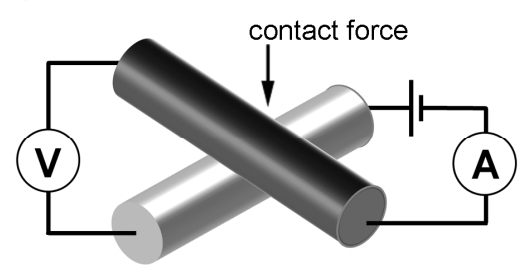

b)

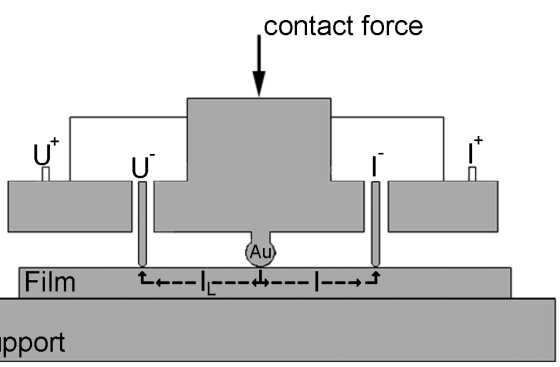

Fig. 5.9 Contact resistance measurement setup with a) crossed cylinders and b) a fourterminal measurement.

In the cross-cylinder setup the contact force is typically measured above $50 \mathrm{~N}$. To come closer to simulate a low contact force application a four-terminal measurement, as shown in Fig. 5.9b), was instead used to measure the contact resistance between 0-10 N in Paper 6. In this setup the film is placed on a fixed support. When the upper part is lowered the spring supported terminals $\mathrm{U}^{-}$and $\mathrm{I}^{-}$ will contact first. These two terminals are isolated from the rest of the upper part. When the gold probe (diameter $4.42 \mathrm{~mm}$ ) is in contact with the film a dc current (I) goes from $\mathrm{I}^{+}$through the probe to $\mathrm{I}^{-}$. The contact resistance is calculated by Ohm's law as for the crossed cylinders by regulating the current and at the same time measuring the voltage between $\mathrm{U}^{-}$and $\mathrm{U}^{+}$. The inner resistance of the gold probe is constant and low and can therefore be ignored. Also the leakage current $\left(\mathrm{I}_{\mathrm{L}}\right)$ from the probe to $\mathrm{U}^{-}$is negligible compared to the current from $\mathrm{I}^{-}$to $\mathrm{I}^{+}$.

As described in Ch. 2, the contact resistance is mainly caused by the constriction resistance. Therefore the contact resistance is not only a property of the contact material, but also of the application (e.g., force applied), used substrate and 
surface contamination. As example Ag deposited on Ni-plated $\mathrm{Cu}$ shows a contact resistance of $1.2 \mathrm{~m} \Omega$ at $10 \mathrm{~N}$ and a probe size of $4.42 \mathrm{~mm}$, while $\mathrm{Ag}$ on steel shows a contact resistance of $3 \mathrm{~m} \Omega$ measured under the same conditions. If the probe size is changed to $1.2 \mathrm{~mm}$ the $\mathrm{Ag}$ on steel will show a contact resistance of $3 \mathrm{~m} \Omega$ already at $1 \mathrm{~N}$. In this thesis an $\mathrm{Ag}$ reference thin film deposited on the same kind of substrate is therefore always used as comparison.

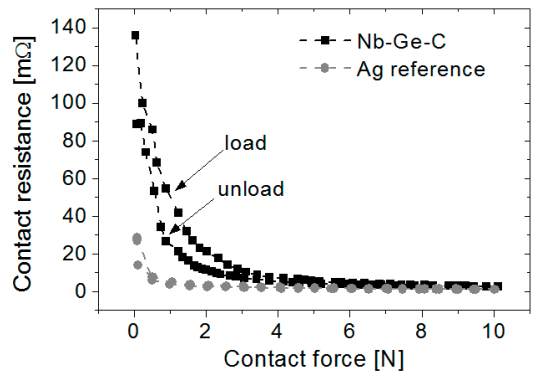

Fig. 5.10 Contact resistance as a function of contact force.

The contact resistance is often plotted as a function of the contact force. A typical behavior of the contact resistance for the films investigated in this thesis is shown in Fig. 5.10. At low contact forces an isolating oxide layer makes the electrical contact area small and the contact resistance high. As the force increases the oxide breaks and there is a rapid decrease in contact resistance. Since the oxide is no longer present and possible also due to plastic deformation of the probe and film, the unload curve will have a lower contact resistance.

\subsection{Nanoindentation}

Nanoindentation is a common way of evaluating the hardness and elastic modulus of thin films. In this technique a diamond tip is pressed into the material resulting in load-displacement curves as the example showed in Fig. 5.11. For the measurements done in these thesis these curves was evaluated according to the Oliver-Pharr method [9]. Then the reduced modulus, $E_{r}$, is given by

$E_{r}=\frac{1}{2} \sqrt{\frac{\pi}{A}}\left(\frac{d F}{d h}\right)$

in which $A$ is the contact area of the tip, and $(d F / d h)$ the contact stiffness of the material. The contact stiffness is determined from the first part of the unloading curve as showed in Fig. 5.11. If the Poisson's ratio (v) of the material is known the elastic modulus, E, of the material can be calculated by inserting $v$ together with the Poisson's ratio $\left(v_{t}\right)$ and elastic modulus $\left(E_{t}\right)$ of the tip in the equation

$\frac{1}{E_{r}}=\frac{1-v^{2}}{E}+\frac{1-v_{t}^{2}}{E_{t}}$ 
The hardness $(H)$ is calculated from the contact area and the maximum load $F_{\max }$

$H=\frac{F_{\max }}{A}$.

Nanoindentation measurements on thin films can easily be influenced by substrate effects if the indentation depth is too large. To avoid this, the maximum load used for the measurements in this thesis was calibrated so the maximum displacement did not exceed $10 \%$ of the total thickness of the film.

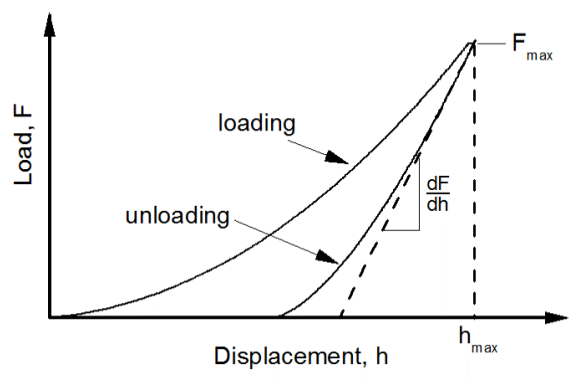

Fig 5.11 Typical load-displacement curve observed under nanoindentation

\section{References}

[1] R. Brydson, Aberration-corrected analytical transmission electron microscopy, John Wiley \& Sons, (2011)

[2] E. Lewin, M. Gorgoi, F. Schäfers, S. Svensson, U. Jansson, Influence of sputter damage on the XPS analysis of metastable nanocomposite coatings, Surf. Coat. Technol. 204 (2009) 455-462

[3] S.D. Walk, J.P. McCaffrey, The small angle cleavage technique applied to coatings and thin films, Thin Solid Films 308-309 (1997) 399-405

[4] J.P. McCaffrey, Small-angle cleavage of semiconductors for transmission electron microscopy, Ultramicroscopy 38 (1991) 149-157

[5] C. Kittel, Introduction to solid state physics $\mathbf{8}^{\text {th }}$ ed., John Wiley \& Sons, (2005)

[6]. B.D. Cullity, Elements of X-ray diffraction, Addison-Wesley, (1956)

[7] M. Birkholz, Thin film analysis by X-ray scattering, John Wiley \& Sons, (2009)

[8] W.G. Sloof, R Delhez, Th.H. de Keijser, E.J. Mittemeijer, Development and partial relaxation of internal stresses in thin $\mathrm{TiC}$ layers chemically vapour deposited on $\mathrm{Fe}-\mathrm{C}$ substrates J. Mater. Sci. 22 (1987) 1701-1706

[9] W.C. Oliver, G.M. Pharr, An improved technique for determining hardness and elastic modulus, J. Mater. Res. 7 (1992) 1564-1583 


\section{Electron-beam-induced crystallization}

In Papers 4 and 5, electron radiation effects on $\mathrm{Me}-\mathrm{Si}-\mathrm{C}(\mathrm{Me}=\mathrm{Nb}$ or $\mathrm{Zr}$ ) are investigated. In both cases crystallization of the amorphous phase in the material was found to occur during electron microscopy analysis. This chapter describes the different processes that were considered as possible causes for the crystallization followed by some comments on how these materials could be studied without microscopy-induced artifacts.

\subsection{Radiation damage processes}

There are several ways in which electron radiation can cause structural and chemical changes to the sample [1-3]. In order to determine the cause of the crystallization observed in the amorphous $\mathrm{Me}-\mathrm{Si}-\mathrm{C}$, the following radiation effects were considered.

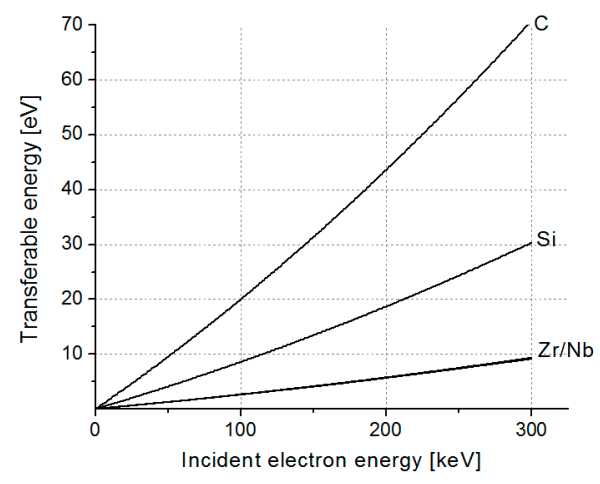

Fig. 6.1 The maximum transferable energy for materials used in this thesis as a function of the energy of the electrons in the electron beam. (The energies are calculated using Eq. 2 in [3])

\subsubsection{Atomic displacement (“knock-on”)}

Elastic scattering process can cause damage to the sample by a "knock-on" process between a nucleus in the sample material and the incident electron. The amount of energy that can be transferred $\left(E_{T}\right)$ will be dependent on the incident 
angle of the electron, the atomic mass, and the energy of the electron. Fig. 6.1 shows the maximum value for $E_{T}$ when an electron hits the nucleus straight on and then backscatters. As can be seen, more energy is transferred for light elements and for higher incident electron energies. If $E_{T}$ is larger than the displacement energy $E_{d}$, the atom will be moved from its position as shown in Fig. 6.2. If this happens in a crystal (Fig. 6.2a)) a Frenkel defect consisting of a vacancy and an interstitial can be created. For a high defect density, the material may undergo amorphization. In an amorphous phase (Fig. 6.2b)), atomic displacement can cause density fluctuation in form of a free volume and an anti-free volume. These density fluctuations may in turn crystallize the material [4].

a)

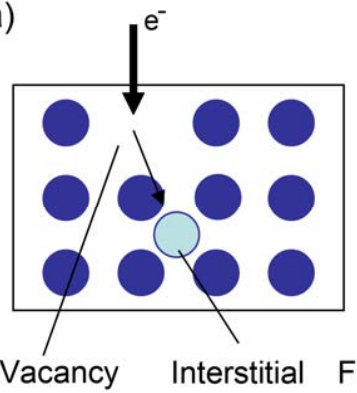

b)

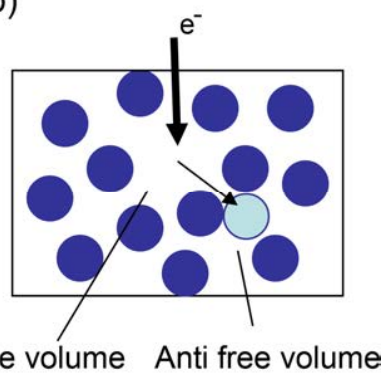

Fig. 6.2 Displacement of atoms may lead to a) creation of Frenkel defects in a crystal, $b$ ) density fluctuations in amorphous materials. (Figure reproduced from [5].)

If the atom hit by the electron is positioned at the surface of the material, the atom can leave the material instead of being displaced. This process is called electron sputtering and the required energy $E_{s}$ is usually much lower than $E_{d}$. Since the electron hitting the atom will be traveling through the sample, sputtering is more likely to occur on the back-side of the specimen.

\begin{tabular}{lccc} 
Element & $\mathbf{E}_{\mathbf{T}}[\mathbf{e V}]$ & $\mathbf{E}_{\mathbf{d}}[\mathbf{e V}]$ & $\mathbf{E}_{\mathbf{s}}[\mathbf{e V}]$ \\
\hline $\mathrm{Ti}$ & $10.9^{\mathrm{b}}$ & $15^{\mathrm{a}}$ & $4-8^{\mathrm{a}}$ \\
$\mathrm{Nb}$ & $5.64^{\mathrm{b}}$ & $24^{\mathrm{a}}$ & $6-12^{\mathrm{a}}$ \\
$\mathrm{C}$ & $43.7^{\mathrm{b}}$ & & \\
$\mathrm{Si}$ & $18.7^{\mathrm{b}}$ & & \\
$\mathrm{Zr}$ & $5.74^{\mathrm{b}}$ & &
\end{tabular}

Table 6.1 Some data for the pure elements. $E_{T}$ is the maximum transferable energy at 200 $k e V, E_{d}$ is the displacement energy and $E_{s}$ is the sputtering energy.

${ }^{a}$ From Table 4.3 in [1]

${ }^{b}$ Calculated from eq. 2 in [3]

Table 6.1 shows the values of for the maximum transferable energy to the discussed elements using incident beam electrons with the energy of $200 \mathrm{keV}$. Shown are also the displacement and sputter energies for some of the elements in their pure form. It should be noted that $E_{d}$ and $E_{s}$ are not strictly valid for the 
investigated materials in this thesis since the chemical environment in an amorphous compound is different compared to the pure elemental states. The values should instead be seen as reasonable estimates.

Displacement and sputter damages are the most common radiation damages seen in metals and the only way to avoid them is to lower the incident electron energy so that the maximum transferable energy does not exceed the displacement energy. In Paper 4 this effect is clearly seen, as the crystallization process is significantly slower if the energy of the beam electrons are lowered from 200 to $80 \mathrm{keV}$. If it is not possible to lower the electron energy below the displacement energy, the electron dose should be minimized for the required resolution in order to reduce damages.

\subsubsection{Specimen heating}

Specimen heating is caused mainly by phonon vibrations in the material. The main parameters that affect the specimen heating are the beam current and the thermal conductivity of the material. This is shown in Fig. 6.3, where materials with different thermal conductivity $\kappa$ (in $\mathrm{W} / \mathrm{m} \cdot \mathrm{K})$ from insulators $(\kappa=0.1)$ to good thermal conductors $(\kappa=100)$ like metals are represented. In Fig. 6.3, the grey region marks the beam current as measured in the TEM used for the main part of the experiments in this thesis. As can be seen from the figure, beam heating should not be a big problem for these currents. However, if a small particle with good thermal conduction is embedded in a matrix of material with lower thermal conductivity, the heating of the particle can be considerable.

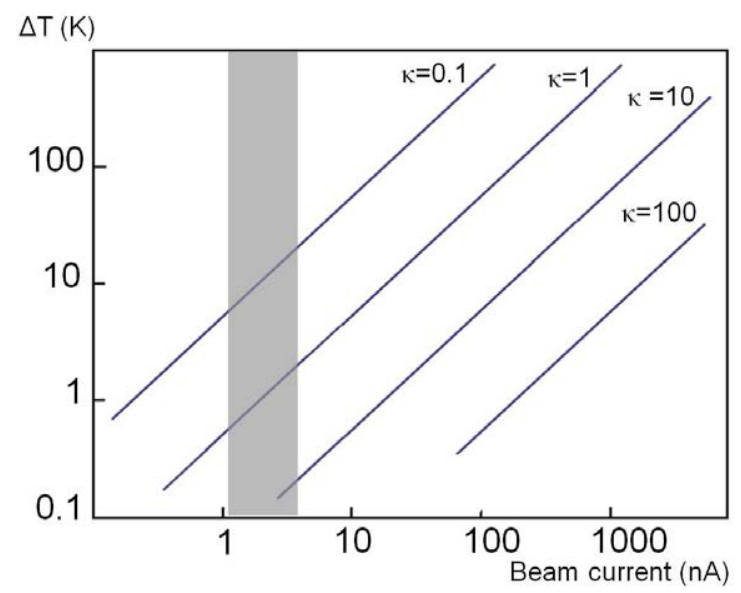

Fig. 6.3 Specimen heating as a function of beam current. The lines marks materials with different thermal conductivity, $\kappa(W / m \cdot K)$. The gray region marks the beam current as measured experimentally for the TEM used in this thesis. (Figure reproduced from [1].)

Even if the heating is small it may be enough to increase the diffusivity of particles in the material and thereby induce changes in the structure. Nagase and 
Umakoshi [5] have, for example, shown that electron beam induced crystallization shows significant temperature dependence by using $\mathrm{MeV}$ electron irradiation on $\mathrm{Fe}-\mathrm{Zr}$-B samples at room temperature and below. The best way to avoid heating is by cooling of the sample. This is done using such a sample holder in the TEM.

\subsubsection{Radiolysis}

The chemistry and structure of covalent and ionic materials can be changed by radiolysis. In this process an inelastic scattered electron excites an electron in the material to make an interband transition. It is then possible for the electrons and holes to recombine and form an anion vacancy and a cation interstitial. The best way to reduce radiolysis is to decrease the initial electron-electron interaction. This can be achieved by having thinner samples or higher acceleration voltage.

\subsection{Viewing non-stable samples}

I have experienced several difficulties in performing the experiments that lead to the conclusions drawn in Paper 4 and 5. First was the problem with viewing the samples in their as-deposited state and later to follow the crystallization process. In this section I describe my solutions to these problems.

\subsubsection{The as-deposited state}

It is of great importance to correctly image the true structure of materials in TEM since conclusions about material properties often are related to the microstructure. Although a material can look amorphous in XRD, high resolution TEM images can sometimes reveal small nanosized grains. In order to acquire these images, focus and astigmatism have to be corrected, which demands adjustments when viewing the specimen. For beam-sensitive samples, this is difficult since their structure is changed due to the beam. Especially difficult in my studies were the $\mathrm{Nb}$-Si-C samples, which showed signs of crystallization within a few minutes at normal imaging conditions.

The solution I used to correctly image the specimens was a so called low-dose technique. Here, the adjustments are made in one area of the specimen and then, after moving to another location, an image is quickly acquired before a critical dose starts the crystallization. The movement of the sample often changes the viewing conditions and therefore this technique usually involves some trial-anderror before a good image can be obtained.

\subsubsection{Observing crystallization}

To make observations of the crystallization process and compare different samples, the electron dose of the specimen should be known. This can be calculated through the beam current, the exposure time, and the irradiated area. 
The beam current should ideally be measured at the position of the sample by trapping all incoming beam-electrons in a Faraday cup. An alternative way, which I have used, is to measure the current coming down to the fluorescent viewing plate. This can be done with the unobstructed beam through a hole in the specimen in connection with the experiment and in this way a regular TEM-sample holder can be used.

During the observation the exposure time was measured. In several of the observations the image had to be corrected for drift of the specimen. This was done manually by tracking the sample continuously.

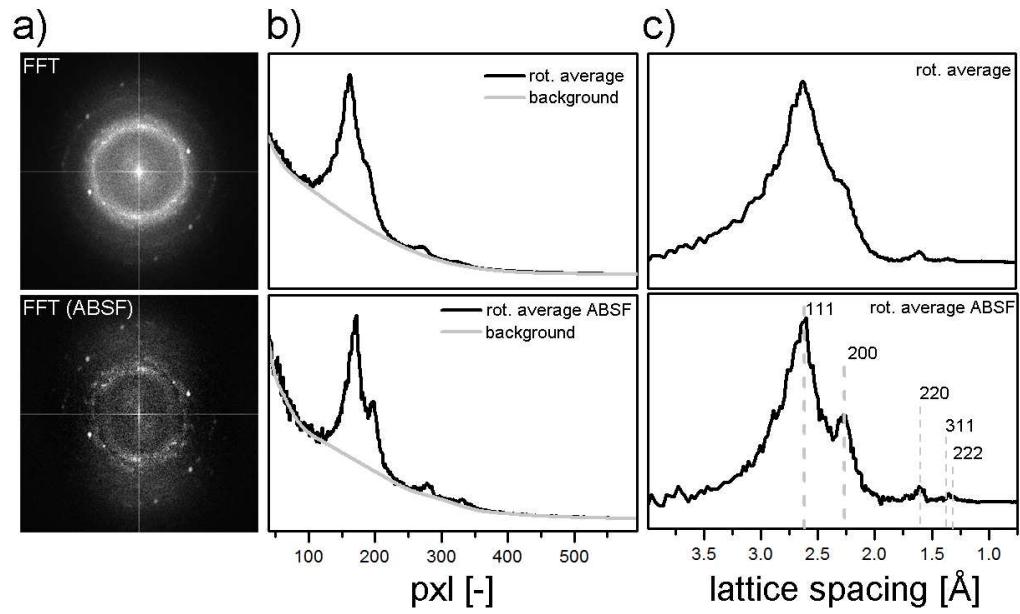

Fig. 6.4 Process for determining the structure and phase of the crystallized material. In the lower row an ABSF filter have been applied to remove background noise from the amorphous phase.

The irradiated area was kept constant to a diameter of $\sim 100 \mathrm{~nm}$ in all experiments. These areas are too small for proper viewing by electron diffraction in a useful way to determine the phases and instead the fast Fourier transforms (FFT) of HRTEM images was used. As an example the FFT for a $\mathrm{Zr}_{.53} \mathrm{Si}_{.20} \mathrm{C}_{.27}$ sample (Paper 5) is shown in Fig. 6.4 a). In the upper row of this figure, the regular FFT is shown. In the lower row an average background subtraction filter (ABSF) have been applied to remove some of the remaining amorphous component. A description of this filter can be found elsewhere [6]. Rather than measuring the reciprocal distance to all observed grains in the FFT, a rotational average was calculated which gives the radial intensity distribution from the center of the FFT as shown in Fig. 6.4 b). The scales in b) are not calibrated. I used an FFT from the single crystal Si substrate taken at the same time as the other FFTs to calibrate the scale and after removing the background the result is presented in Fig. $6.4 \mathrm{c}$ ). In this way I show that the best match is an fcc structure with an lattice spacing of $4.58 \AA$, which among the possible candidates fits best to the $\mathrm{NaCl}$ (B1) structure of $\mathrm{ZrC}_{\mathrm{x}}$. 


\section{References}

[1] D.B Williams, C.B. Carter, Transmission electron microscopy: a textbook for materials science, $2^{\text {nd }}$ ed., Springer, (2009)

[2] M.R. McCartney, P.A. Crozier, J.K. Weiss, D.J. Smith, Electron-beam-induced reactions at transition-metal oxide surfaces, Vacuum 42 (1991) 301-308

[3] R.F. Egerton, P. Li, M. Malac, Radiation damage in the TEM and SEM, Micron 35 (2004) 399-409

[4] T. Nagase, T. Sanda, A. Nino, W. Qin, H. Yasuda, H. Mori, Y. Umakoshi, J.A. Szpunar, $\mathrm{MeV}$ electron irradiation induced crystallization in metallic glasses: Atomic structure, crystallization mechanism and stability of an amorphous phase under irradiation, $J$. Non-Cryst. Solids 358 (2012) 502-518

[5] T. Nagase, Y. Umakoshi, Temperature dependence in density-fluctuation-induced crystallization in metallic glass by MeV electron irradiation, Intermetallics 18 (2010)

1803-1808

[6] R. Kilaas, Optimal and near-optimal filters in high-resolution electron microscopy, J. Microsc. 190 (1997) 45-51 


\section{Summary and contribution to the field}

This thesis concerns the microstructure of transition metal carbide based thin film materials. This is a large class of materials with interesting properties for both electrical and mechanical applications. The properties depend to large extent on the microstructure and the ability of tailoring the structure by appropriate choice of composition with different alloying elements makes it an interesting field to study. For industrially relevant substrates, the deposition temperature is usually kept low $\left(<400{ }^{\circ} \mathrm{C}\right)$. One way to do this is to use magnetron sputtering. However, the evolution of film properties and structure can be rather complex for both binary and ternary systems, when deposited at temperatures far from thermal equilibrium. My work has therefore been to increase the knowledge of the structure and properties of transition metal carbide nanocomposites when deposited with magnetron sputtering at these relatively low deposition temperatures.

\subsection{Nb-C as electrical contact material}

For electrical contact applications, Ti-C based nanocomposites with addition of, e.g., Si have attracted attention with promising results [1-5]. However, both Ti and $\mathrm{Si}$ form insulating oxides, which can cause problems for low contact force applications. Preliminary results from Lewin indicate also the $\mathrm{Nb}-\mathrm{C}$ system to be a good candidate as electrical contact material [6]. In Paper 1, I therefore investigate the $\mathrm{Nb}-\mathrm{C}$ system more thoroughly with a focus on relating the structure to electrical and mechanical properties.

This is done by depositing Nb-C thin films with unbalanced magnetron sputtering from two elemental targets using a substrate bias of $-50 \mathrm{~V}$ and a substrate temperature of $300{ }^{\circ} \mathrm{C}$. The result is a nanocomposite consisting of crystalline $\mathrm{NbC}$ grains surrounded by a matrix of amorphous $\mathrm{C}$. XRD shows that the $\mathrm{NbC}$ grains are of the $\mathrm{B} 1(\mathrm{NaCl})$ structure. With increased $\mathrm{C}$ content (from 43 to 64 at.\% C), TEM shows a change from grains elongated $(\sim 75 \mathrm{~nm})$ in the growth direction to small $(3-5 \mathrm{~nm})$ equiaxed grains.

By comparing the areas of the $\mathrm{C}-\mathrm{C}$ and $\mathrm{Nb}-\mathrm{C}$ peaks in the $\mathrm{C} 1 \mathrm{~s}$ spectra the relative amount of amorphous carbon can be calculated from the XPS data. Although an 
increase of amorphous $\mathrm{C}$ with increased $\mathrm{C}$ content was found, the surrounding matrix remained at almost the same thickness due to the reduced size of the $\mathrm{NbC}$ grains.

The changes in microstructure are found to be similar to those observed in the $\mathrm{TiC}$ system. One important difference is the thickness of the matrix, which is much thinner in the case of NbC/a-C compared to TiC/a-C. This can be explained by a larger homogeneity range for $\mathrm{TiC}$, which makes it easier to create $\mathrm{C}$ vacancies and therefore allow more free $\mathrm{C}$ to cluster during growth. The thinner matrix can be used to explain the lower resistivity of NbC/a-C $(260-1200 \mu \Omega \mathrm{cm})$ compared to TiC/a-C (1200-1600 $\mu \Omega \mathrm{cm})$ since an amorphous $C$ matrix softens the structure and is less conducting than the $\mathrm{MeC}$ grains. Also, the contact resistance of the best $\mathrm{Nb}-\mathrm{C}$ film $(140 \mu \Omega)$ is good and comparable to a Ag reference $(45 \mu \Omega)$ at a contact force of $100 \mathrm{~N}$.

I have thereby shown that nanocomposites consisting of $\mathrm{NbC} / \mathrm{a}-\mathrm{C}$ can function as an electrical contact material and that the electrical and mechanical properties can be tuned by a suitable choice of composition.

\subsection{Ternary systems}

The addition of a third element into a metal carbide increases the complexity, but also the ability to design a multifunctional material. For example, $\mathrm{Si}$ is sometimes added in the well-studied Ti-C system to further tailor the properties of the formed Ti-Si-C nanocomposite material by decreasing the grain size of the $\mathrm{TiC}$ grains [7]. In the formed nanocomposite system some $\mathrm{Si}$ can be incorporated into the $\mathrm{TiC}_{\mathrm{x}}$ crystalline grains. There are, however, different opinions on whether $\mathrm{Si}$ is incorporated on the $\mathrm{Ti}[8,9]$ or $\mathrm{C}[10-13]$ site.

To solve this problem and to investigate how $\mathrm{Si}$ segregates to form a nanocomposite structure, I used a model system of epitaxial $\mathrm{TiC}_{\mathrm{x}}(\mathrm{x} \sim 0.7)$ into, which small amounts of $\mathrm{Si}$ is incorporated (Paper 2). Here, the Ti-Si-C films were deposited from elemental targets at a substrate temperature of $350{ }^{\circ} \mathrm{C}$. The voltage on the $\mathrm{Si}$ target was changed between the depositions in order to control the amount of incorporated $\mathrm{Si}$. For up to 4 at.\% $\mathrm{Si}$, the epitaxy is at least locally sustained. XRD shows an expansion of the lattice parameter of the $\mathrm{TiC}_{\mathrm{x}}$ indicating that some of the $\mathrm{Si}$ is incorporated on the $\mathrm{C}$ sites in the $\mathrm{TiC}_{\mathrm{x}}$ to form a $\mathrm{Ti}(\mathrm{Si}, \mathrm{C})$ phase. The formation of a $\mathrm{Ti}(\mathrm{Si}, \mathrm{C})$ phase is supported by theoretical calculations of the preferred position of $\mathrm{Si}$ if the $\mathrm{Si}$ atoms are trapped in a cubic $\mathrm{TiC}_{0.75}$ structure. For an increasing Si content above and equal to 4 at. $\%$, the epitaxy is gradually lost and the $\mathrm{Si}$ segregates to the column boundaries of the $\mathrm{TiC}_{\mathrm{x}}$ grains forming a nanocomposite structure.

As seen in Paper 2, an increase of Si hinders the growth of $\mathrm{TiC}$ and this is also generally observed for other $\mathrm{MeC}$ in other Me-Si-C systems. A systematic study of the influence of $\mathrm{Si}$ on the structure and mechanical properties has been made in the $\mathrm{Zr}-\mathrm{Si}$-C system $[14,15]$. The results show that a transition to a completely 
amorphous material occurs for Si contents higher than 15 at.\%. For the amorphous structure, a random network of different bonds could be modelled. The results also show that some mechanical properties depend on the amount of strong $\mathrm{Si}-\mathrm{C}$ bonds in the structure.

I wanted to see if these results are also true for other Me-Si-C systems and in Paper $3 \mathrm{I}$ therefore investigated $\mathrm{Nb}-\mathrm{Si}-\mathrm{C}$ thin films. In this paper two series of $\mathrm{Nb}-\mathrm{Si}-\mathrm{C}$ thin films were deposited from elemental targets with DC magnetron sputtering at a substrate temperature of $300{ }^{\circ} \mathrm{C}$. In the first series the $\mathrm{C}$ content was kept constant at $\sim 55$ at. $\%$ and the $\mathrm{Nb} / \mathrm{Si}$ ratio was varied. In the second series the $\mathrm{Si}$ content was instead fixed $\sim 45$ at. $\%$ and the $\mathrm{C} / \mathrm{Nb}$ ratio was changed.

For $\mathrm{Si}$ contents below 25 at.\%, the films have a nanocomposite structure with cubic $\mathrm{NbC}$ grains embedded in an amorphous matrix of $\mathrm{SiC}$ and $\mathrm{C}$. With a $\mathrm{Si}$ content above 25 at.\% the films are amorphous when viewed in HRTEM. With increase of $\mathrm{Si}$ the resistivity increases from $211 \mu \Omega \mathrm{cm}$ to $3215 \mu \Omega \mathrm{cm}$. A drop in the hardness was also observed with hardness between 18-19 GPa for the Si containing films compared to $22 \mathrm{GPa}$ for the binary $\mathrm{Nb}-\mathrm{C}$ film. The mixture of chemical bonds in the amorphous $\mathrm{Nb}-\mathrm{Si}-\mathrm{C}$ films suggests that the structure is similar to the network structure seen in the $\mathrm{Zr}-\mathrm{Si}-\mathrm{C}$ films. The amount of $\mathrm{Si}$ required to form an amorphous $\mathrm{Me}-\mathrm{Si}-\mathrm{C}$ film is, however, higher in the case of $\mathrm{Nb}-\mathrm{Si}-\mathrm{C}(>25$ at.\%) than for Zr-Si-C (>15 at.\%). This indicates a lower glassforming ability for $\mathrm{Nb}$ compared to $\mathrm{Zr}$.

While the hardness of the $\mathrm{Nb}-\mathrm{Si}-\mathrm{C}$ and $\mathrm{Zr}-\mathrm{Si}-\mathrm{C}$ films seems to depend on the amount of Si-C bonds rather than the choice of transition metal, the elastic modulus shows a dependency on the used transition metal. My results thus suggest that it should be possible to produce high wear resistant films (high $\mathrm{H} / \mathrm{E}$ and $\mathrm{H}^{3} / \mathrm{E}^{2}$ ) by appropriate choice of composition and transition metal.

To extend the knowledge of ternary Me-C based systems and study the influence of different components I decided to change $\mathrm{Si}$ for $\mathrm{Ge}$ as A-component in the $\mathrm{Nb}-\mathrm{A}-\mathrm{C}$ system (Paper 6). Nb-Ge-C thin films were therefore deposited from elemental targets by dc magnetron sputtering at a substrate temperature of $200{ }^{\circ} \mathrm{C}$. The Ge content was changed between $0-30$ at.\% in three series with different $\mathrm{C} / \mathrm{Nb}$ ratios. The films were found to have a nanocomposite structure with substoichiometeric $\mathrm{NbC}_{\mathrm{x}}$ in a nm-thick matrix of amorphous $\mathrm{C}$ and Ge. The binary $\mathrm{Nb}-\mathrm{C}$ films have a (111) preferred crystallographic orientation with $\mathrm{NbC}_{\mathrm{x}}$ grains that are elongated in the growth direction. With the addition of $\mathrm{Ge}$ the grains becomes equiaxed and with random orientation. A small addition of Ge gives a more porous structure, but with further increase in the Ge content the films show a less columnar and denser structure. Due to the porosity of the material a high level of $\mathrm{O}$ contamination (up to 22 at.\%) was seen. The porosity and oxygen content affects the resistivity, which varies between $470-1735 \mu \Omega \mathrm{cm}$ depending on the porosity. The lowest contact resistance $(1.7 \mathrm{~m} \Omega)$ was found for the binary films. The contact resistance was not affected by the change in porosity, but increased with $\mathrm{Ge}$ content. Looking at the influence of $\mathrm{Ge}$ compared to $\mathrm{Si}, \mathrm{Ge}$ in a similar way to $\mathrm{Si}$ decreases the size of the crystalline $\mathrm{NbC}$ grains. However, a transition to 
a completely amorphous material is never seen even at high Ge contents $(\sim 30$ at.\%). Another dissimilarity is that while $\mathrm{Si}$ bond to $\mathrm{C}$ and form a matrix of a-SiC, Ge tends to bond to Ge.

\subsection{Artifacts from characterization}

I discovered a potentially important problem of introducing electron-beaminduced crystallization as an artifact when studied amorphous $\mathrm{Nb}-\mathrm{Si}$ - $\mathrm{C}$ samples in high resolution TEM. The possibility of such artifacts is known to be induced if the interaction between the electron-beam and the sample is too strong [16-18], but not well reported for ternary transition metal carbides. Since TEM offers high spatial resolution it is used as a standard technique to characterize the structure of amorphous and nanocrystalline materials and it is therefore of general interest to know if ternary transition metal carbides are susceptible the energetic electron irradiation during HRTEM studies.

Thus, in Paper 4 and 5 effects of the electron beam in high resolution transmission electron microscopy under normal imaging conditions on the amorphous phase in transition metal silicon carbide are studied. For this purpose, two different transition metals, $\mathrm{Zr}$ and $\mathrm{Nb}$ were selected. The electron beam induced formation of crystalline $\mathrm{MeC}$ grains in both the $\mathrm{Nb}-\mathrm{Si}-\mathrm{C}$ and the $\mathrm{Zr}-\mathrm{Si}-\mathrm{C}$ films. The causes of the crystallization were investigated by studying at the effect of different dose as well as different energy of the electrons in the electron beam. It was found that different beam currents with the same dose generate similar crystallization. If the electron energy is lowered from $200 \mathrm{keV}$ to $80 \mathrm{keV}$, the crystallization is remarkably reduced for the same dose. The effect of heating was tested by in-situ annealing of the sample in the TEM. It was found that the crystallization process started between $400-600{ }^{\circ} \mathrm{C}$. However, this process was much slower than for the beam-induced crystallization. The conclusion is that heating is not the main cause of the crystallization. Instead the energy dependence suggests that the crystallization is produced by a knock-on process, where energy from one elastically scattered beam electron is transferred to one of the specimen atoms causing displacement of this atom.

Looking at compositional effects it is clearly seen that the Zr-containing specimens are much more stable than the Nb-Si-C specimens. Also, a higher amount of Si stabilizes the amorphous structure, but to much less extent.

Kádas et al. [15] showed with good agreement to experimental data that the structure of the amorphous state of $\mathrm{Zr}-\mathrm{Si}-\mathrm{C}$ can be simulated as a random distribution of atoms. Since the relative amounts of bonds in XPS are similar in the $\mathrm{Nb}-\mathrm{Si}-\mathrm{C}$ case I assume that the random distribution also applies for $\mathrm{Nb}-\mathrm{Si}-\mathrm{C}$ (Paper 3). During electron irradiation mainly $\mathrm{C}$ and possibly also $\mathrm{Si}$ are displaced by collisions with electrons from the electron beam. This creates density fluctuations that increase the ability of the surrounding Me atoms to move into this place and form a carbide crystallite by nucleation and growth. The growing $\mathrm{MeC}$ grains requires less molar volume compared to the starting amorphous matrix, 
which increase the length by which atoms from the neighboring matrix need to migrate. This, together with the increase the in concentration of $\mathrm{Si}$ at the carbide/matrix interface reduces the crystallization rate. At a certain build-up in $\mathrm{Si}$ concentration, further grain growth is no longer possible and the crystallization eventually stops. Since the amorphous $\mathrm{Nb}-\mathrm{Si}-\mathrm{C}$ films are less stable than the amorphous $\mathrm{Zr}-\mathrm{Si}-\mathrm{C}$ films nucleation of $\mathrm{NbC}$ grains will occur more often resulting in a larger number and smaller sized grains.

The time to obtain a critical dose in the $\mathrm{Nb}-\mathrm{Si}-\mathrm{C}$ case was only a few minutes. Therefore, I draw the conclusion that great care should be used in imaging these kinds of materials for a correct structure characterization. Also, the effect of ion irradiation caused by the ion milling in the sample preparation were investigated in Paper 4 since ion milling have been shown to introduce artifacts in XPS C1s spectra of metal carbides [19]. This was done by comparing samples made in the conventional way with samples made by the small angle cleavage technique. However, no large difference between the two methods was found.

\section{References}

[1] P. Eklund, J. Emmerlich, H. Högberg, O. Wilhelmsson, P. Isberg, J. Birch, P. O. A Persson, U. Jansson, L. Hultman, Structural, electrical, and mechanical properties of nc-TiCa-SiC nanocomposite thin films, J. Vac. Sci. Technol., B 23 (2005) 2486-2495 [2] J. Lauridsen, J. Lu, P. Eklund, L. Hultman, Å. Öberg, M. Lindgren, L. Fast, E. Lewin, U. Jansson, Deposition of Ti-Si-C-Ag nanocomposite coatings as electrical contact material, (56th IEEE Holm Conference on Electrical Contacts, 2010)

[3] J. Lauridsen, N. Nedfors, U. Jansson, J. Jensen, P. Eklund, L. Hultman, Ti-B-C nanocomposite coatings deposited by magnetron sputtering, Appl. Surf. Sci. 258 (2012) 9907-9912

[4] A. Öberg, A. Kassman, B. André, U. Wiklund, M. Lindquist, E. Lewin, U. Jansson, H. Högberg, T. Joelsson, H. Ljungcrantz, Conductive nanocomposite ceramics as tribological and electrical contact materials, Eur. Phys. J.: Appl. Phys. 49 (2010) 22902 [5] E. Lewin, E. Olsson, B. André, T. Joelsson, Å Öberg, U. Wiklund, H. Ljungcrantz, U. Jansson, Industrialisation study of nanocomposite nc-TiC/a-C coatings for electrical contact applications, Plasma Processes Polym. 6 (2009) 928-934

[6] E. Lewin, Design of carbide-based nanocomposite coatings, PhD Thesis, Acta Universitatis Upsaliensis, (2009)

[7] W. Gulbinski, T. Suszko, A. Gilewicz, B. Warcholinski, Z. Kuklinski, Structure and high-temperature tribological behavior of Ti-Si-C nanocomposite thin films, Surf. Coat. Technol. 200 (2006) 4179-4184

[8] M. W. Barsoum, T. El-Raghy, L. Farber, M. Amer, R. Christini, A. Adams, The topotactic transformation of $\mathrm{Ti}_{3} \mathrm{SiC}_{2}$ into a partially ordered cubic $\mathrm{Ti}\left(\mathrm{C}_{0.67} \mathrm{Si}_{0.06}\right)$ phase by the diffusion of Si into molten cryolite, J. Electrochem. Soc. 146 (1999) 3919-3923

[9] L. Cunha, F. Vaz, C. Moura, D. Munteanu, C. Lonescu, J. P. Rivière, E. Le Bourhis, Ti$\mathrm{Si}-\mathrm{C}$ thin films produced by magnetron sputtering: Correlation between physical properties, mechanical properties and tribological behavior, J. Nanosci. Nanotechnol. 10 (2010) 2926-2932 
[10] M. Witthaut, R. Weiß, E. Zimmermann, A. Von Richthofen, D. Neuschütz, The formation of interface phases in the diffusion couple Ti-SiC, Z. Metallkd. 89 (1998) 623-628

[11] R. Yu, L. L. He, H. Q. Ye, Effects of Si and Al on twin boundary energy of TiC, Acta Mater. 51 (2003) 2477-2484

[12] Z. Zhang, Y. Luo, C. Xu, Phase and morphology evolution of TiC in the Ti-Si-C system, Int. J. Refract. Met. Hard Mater. 34 (2012) 32-35

[13] H. M. Ding, T. J. Ci, K. Y. Chu, J. F. Wang, First-principles study of doping and distribution of Si in TiC, Mater. Sci. 31 (2013) 259-263

[14] M. Andersson, S. Urbonaite, E. Lewin, U. Jansson, Magnetron sputtering of Zr-Si-C thin films, Thin Solid Films 520 (2012) 6375-6381

[15] K. Kádas, M. Andersson, E. Holmström, H. Wende, O. Karis, S. Urbonaite, S. M. Butorin, S. Nikitenko, K. O. Kvashnina, U. Jansson, O. Eriksson, Structural properties of amorphous metal carbides: Theory and experiment, Acta Mater. 60 (2012) 4720-4728 [16] T. Nagase, T. Sanda, A. Nino, W. Qin, H. Yasuda, H. Mori, Y. Umakoshi, J. A. Szpunar, MeV electron irradiation induced crystallization in metallic glasses: Atomic structure, crystallization mechanism and stability of an amorphous phase under the irradiation, J. Non-Cryst. Solids 358 (2012) 502-518

[17] I. T. Bae, M. Ishimaru, Y. Hirotsu, Structural changes of $\mathrm{SiC}$ under electron-beam irradiation: Temperature dependence, Nucl. Instrum. Methods Phys. Res., Sect. B 250 (2006) 315-319

[18] R. F. Egerton, Mechanisms of radiation damage in beam-sensitive specimens, for TEM accelerating voltages between 10 and 300 kV, Microsc. Res. Tech. 75 (2012) 15501556

[19] E. Lewin, P. O. Å Persson, M. Lattemann, M. Stüber, M. Gorgoi, A. Sandell, C. Ziebert, F. Schäfers, W. Braun, J. Halbritter, S. Ulrich, W. Eberhardt, L. Hultman, H. Siegbahn, S. Svensson, U. Jansson, On the origin of a third spectral component of C1s XPS-spectra for nc-TiC/a-C nanocomposite thin films, Surf. Coat. Technol. 202 (2008) $3563-3570$ 


\section{Included Papers}

The articles associated with this thesis have been removed for copyright reasons. For more details about these see:

http://urn.kb.se/resolve?urn=urn:nbn:se:liu:diva-104929 